\title{
BIOCHEMICAL INTERRUPTION OF MEMBRANE PHOSPHOLIPID RENEWAL IN RETINAL PHOTORECEPTOR CELLS ${ }^{1}$
}

\author{
GLEN A-WEN PU' ${ }^{2}$ AND RICHARD H. MASLAND \\ Department of Neurosurgery, Massachusetts General Hospital, and Department of Physiology, Harvard Medical School, \\ Boston, Massachusetts 02114
}

Received July 29, 1983; Revised December 19, 1983; Accepted January 10, 1984

\begin{abstract}
The rabbit retina's synthesis of new phosphatidylcholine from extracellular choline was interrupted by an intravitreal injection of the choline analogue hemicholinium-3. This disrupted the process by which new membrane is added to the rod photoreceptor outer segments and eventually caused outer segment degeneration. During the first 2 days after hemicholinium-3 was injected, rows of vesicles replaced the newly formed membrane discs at the outer segment's base. The region of vesicles then expanded, and the distal outer segment detached and was quickly phagocytosed by the pigment epithelium. Two weeks after hemicholinium-3 injection, all of the retina's outer segments had been lost and the inner segments were reduced in length.

The threshold concentration of hemicholinium-3 was approximately $20 \mu \mathrm{M}$ intraocularly. At this dose, the cell bodies, intracellular organelles, and synapses of the rod cells survived. A small group of amacrine cells, possibly those that synthesize acetylcholine, became pyknotic; but the other retinal neurons remained normal to both light and electron microscopy even upon exposure to intraocular concentrations as high as $1 \mathrm{~mm}$. Biochemical experiments indicated that at $20 \mu \mathrm{M}$ hemicholinium -3, the perturbation of choline metabolism is partial and transient. That it has major selective consequences for the outer segments probably reflects the large amount of new phospholipid required for renewal of their membranes.

The selectivity of the lesion was also evidenced by electrophysiological activity recorded from hemicholinium-3-treated retinas. Hemicholinium-3 was injected in vivo, and at various times retinas were isolated and incubated in vitro. The normal components of the electroretinogram were observed, but its amplitude rapidly declined; 12 days after injection, no response to light could be detected. Spontaneous firing of single ganglion cells was observed at all times following hemicholinium-3 injection. As the outer segments degenerated and the threshold of the electroretinogram rose, the thresholds of the ganglion cells also rose, but normal ganglion cell receptive fields could sometimes be plotted. Fourteen days after injection, when all of the outer segments were gone, ganglion cell responses to bright light could still be recorded; their thresholds were about 3.5 log units above normal. This finding is consistent with a previous report of light-evoked responses in mice after outer segment degeneration. An interpretation is that the intact protein synthetic machinery of the photoreceptor cell inserts enough of the necessary molecules into the inner segment or perikaryal membrane to perform at least a rudimentary phototransduction.

Loss of the outer segments was followed by their slow regeneration. During a 60-day period, some cells achieved half of their normal outer segment length, with a partial recovery of the electroretinogram and the sensitivity of the ganglion cell response. The ordered structure of the rod outer segment discs was essentially normal. Apparently the developmental program of the photoreceptor neuron allows resynthesis of this complex organelle after its total destruction.

Cones were more sensitive to hemicholinium-3 than rods. Their outer segments were disrupted almost simultaneously throughout and were rapidly shed. Their cell bodies then degenerated.
\end{abstract}

The light-sensitive element of the vertebrate photoreceptor cell is the outer segment, an elongated organelle

\footnotetext{
${ }^{1}$ This work was supported by National Institutes of Health Grants RO1-EY01075 and 5F32EY-05248, and by a Research Career Development award to R. H. M.

${ }^{2}$ To whom correspondence should be directed, at his current address: Department of Ophthalmology, Baylor College of Medicine, Houston, TX 77030.
}

specialized to expose a large amount of membrane-bound visual pigment to the environment. The outer segment contains a tightly packed stack of disc-shaped phospholipid bilayer membranes. These membranes are renewed throughout life by a process in which packets of membrane are shed from the tip of the outer segment and new membranes are added at the base (Young, 1967). A typical mammalian rod replaces about $10 \%$ of its outer 
segment discs daily. To keep pace with the demands of outer segment renewal, the photoreceptor cell must synthesize, transport, and assemble large amounts of new membrane; to replace the membrane lost by shedding, a typical mammalian rod must replace somewhere between 250 and $800 \mu \mathrm{m}^{2}$ of membrane each day. Because it contains large amounts of membrane at a site remote from their synthesis, the photoreceptor cell is favorable for study of the mechanisms by which neuronal membranes are assembled and maintained.

In the photoreceptor cell, as in all neurons, a major fraction of the total membrane lipid is phosphatidylcholine, much of which is synthesized de novo from diglyceride and free choline (Anderson et al., 1980b). Since the cells cannot synthesize free choline, the large amount of membrane required for outer segment renewal requires a very effective net inward choline transport, and this is mediated by a carrier that behaves kinetically like the "high affinity uptake" systems observed in neurons that secrete acetylcholine. Mammalian photoreceptor cells do not synthesize acetylcholine; instead, a large fraction of the choline that enters the cell is phosphorylated and is destined for outer segment phosphatidylcholine (Masland and Mills, 1980).

This suggested that interference with the retina's choline transport might provide a rather selective way to influence the addition of new membrane to the outer segment. The choline analog hemicholinium-3 (HC-3) is known to deprive cells of choline by competitive binding to the carrier that transports choline through the membrane (Birks and MacIntosh, 1961; Guyenet et al., 1973; Holden et al., 1975). We exposed retinas to hemicholinium -3 and found that there was indeed a selective effect on the photoreceptors, as evidenced by loss of the outer segments within 2 weeks after treatment. We therefore carried out a longitudinal study of retinas transiently exposed to hemicholinium-3, asking what the fine-structural consequences would be of loss of the photoreceptor cell's ability to synthesize a major phospholipid, in what way the retina's physiology would be affected by the resulting lesion, and how the mechanisms of outer segment renewal would respond to a sudden loss of the outer segment.

\section{Materials and Methods}

Unless otherwise specified, all experiments were carried out on 4- to 6-pound New Zealand White rabbits.

Intraocular injections of hemicholinium-3 $\left(2,2^{\prime}-\left(4,4^{\prime}\right.\right.$ biphenylene)bis (2-hydroxy-4, $4^{\prime}$-dimethyl morpholinium)) bromide (Aldrich) were made. The rabbit was sedated with pentobarbital, and the eyes were anesthetized by topical application of $0.5 \%$ proparacaine hydrochloride ophthalmic solution (Squibb). The eye was rotated, and a hole was pierced in the sclera by a number 23 hypodermic needle. The tip of a 10- $\mu$ l Hamilton syringe was inserted through the hole and centered in the vitreous body under visual control. Usually $10 \mu \mathrm{l}$ of a freshly prepared aqueous solution were injected over a period of about $30 \mathrm{sec}$, after which the needle was slowly withdrawn. A topical ophthalmic penicillin ointment (IIotycin) was then applied to prevent infection.

The time course of the retina's exposure to $\mathrm{HC}-3$ was evaluated in experiments using $\left[{ }^{3} \mathrm{H}\right] \mathrm{HC}-3$, which was obtained commercially by a custom synthesis (Amersham), using methylation of bisnorhemicholinium-3 with $\left[{ }^{3} \mathrm{H}\right]$ methyl iodide. We further purified the isotopically labeled compound by high voltage electrophoresis as described below. Authentic $\mathrm{HC}-3$ was identified by iodine staining in a spot about $20 \mathrm{~cm}$ from the origin. The purified isotope was eluted, dried down, and made up as a $3.125 \mathrm{~mm}$ solution in water by the addition of carrier (final specific activity $=64 \mathrm{mCi} / \mathrm{mmol}$ ). Ten microliters of this solution were injected into the eye to yield an intraocular concentration of $20 \mu \mathrm{M}$. At varying times after the injection, the eye was removed and hemisected, and the vitreous body, which in the rabbit is quite coherent, was lifted out. The retina was removed under oxygenated medium and rinsed twice in medium. All solutions used for rinsing the retina were combined with the vitreous body. This mixture was homogenized, and the volume was adjusted to $50 \mathrm{ml}$. Triplicate $1-\mathrm{ml}$ aliquots of this mixture were taken for scintillation counting. The results are shown in Figure 1. HC-3 cleared from the vitreous with a half-time of not more than 12 hr. For comparison, the clearing of inulin, an inert marker, is also shown. The rapid clearance of $\mathrm{HC}-3$ is consistent with previous measurement of the clearance of similar molecules from the rabbit eye (Maurice, 1976).

Intraocular concentrations given in the text are calculated on the assumption that the injected solution diffuses uniformly within a rabbit eye of $1.5 \mathrm{ml}$ volume. For obvious reasons, such values are approximate; they have the virtue of allowing ready comparison with the studies in which HC-3 was applied in vitro. It should be noted that the length of time a small molecule remains within the eye will depend heavily on the volume of the vitreous body and the rate of aqueous flow. The doses of $\mathrm{HC}-3$ required to cause the effects described here in the rabbit are probably different for animals with larger or smaller eyes, because of the differing times for which the retina is exposed to the drug. An advantage of the rabbit in this context is that this eye is relatively large; in animals with small eyes the vitreous chamber is largely filled by the lens, so that intraocular injection will probably achieve a less uniform distribution of the test compounds. Even in the rabbit there was some variability from region to region. For that reason care must be taken to sample locations distributed across the retinal surface (see "Results").

Morphological techniques. Fixation of the retina was by intracardiac perfusion with $2 \%$ glutaraldehyde in 0.18 M phosphate buffer ( $\mathrm{pH} 7.2$ ), unless otherwise noted. During perfusion, intraocular pressure was lowered by paracentesis of the anterior chamber. After perfusion, the eye was immersed in fixative, and the retina and pigment epithelium were dissected away from the sclera. Primary glutaraldehyde fixation was for 2 to $3 \mathrm{hr}$. The retina was then rinsed, postfixed in $2 \% \mathrm{OsO}_{4}$ in phosphate buffer for $1 \mathrm{hr}$, and dehydrated through an ethanol series. Tissue was stained en bloc overnight in 5\% uranyl acetate in $70 \% \mathrm{EtOH}$. Dehydration was then continued. Just prior to embedding in Epon-Araldite, the tissue was systematically cut into pieces about $2 \mathrm{~mm}^{2}$. On a few occasions, fixation was by direct immersion into $2 \% \mathrm{OsO}_{4}$ 

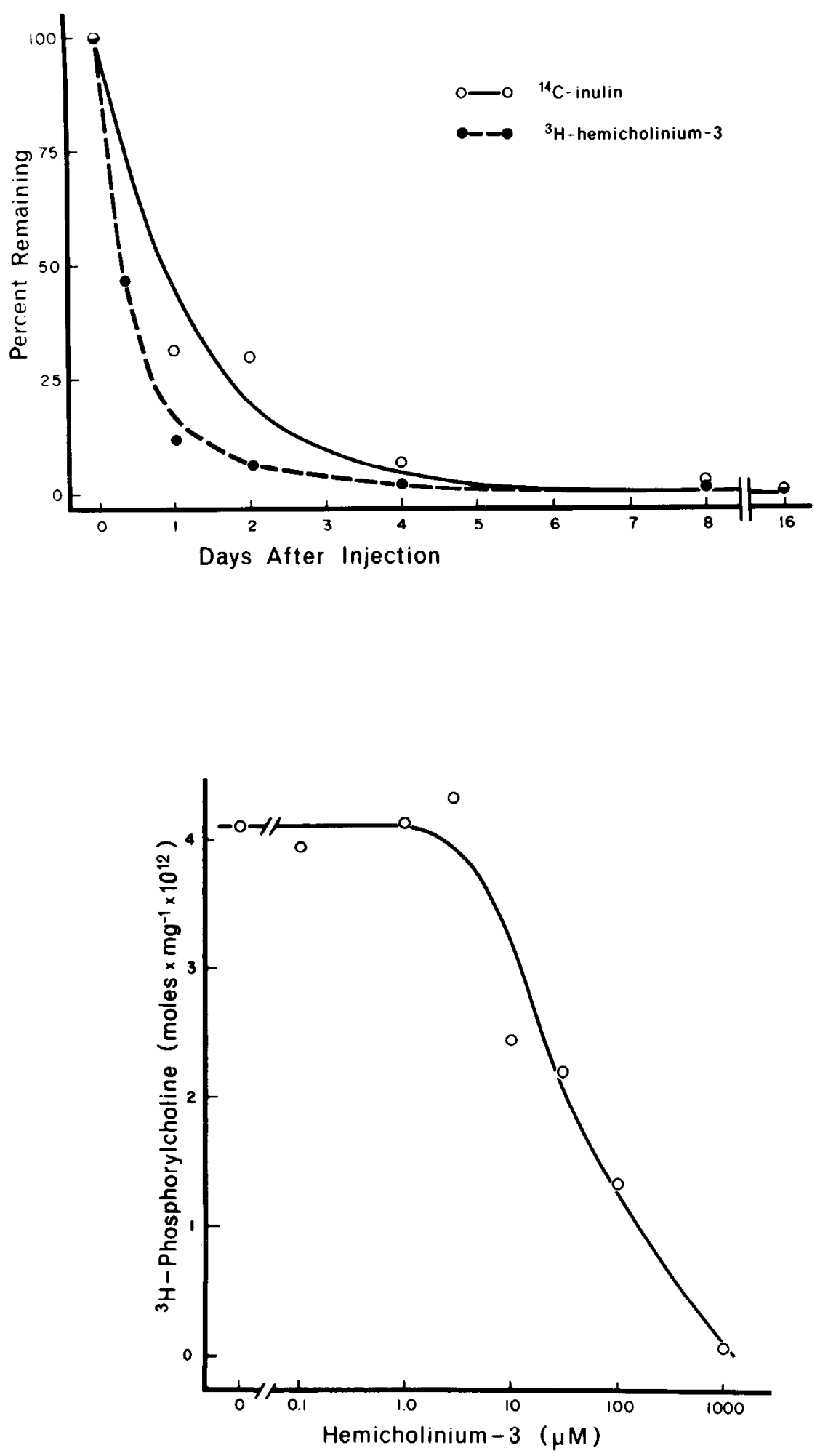

2

Figure 1. The clearance of $\left[{ }^{3} \mathrm{H}\right]$ hemicholinium-3 and $\left[{ }^{14} \mathrm{C}\right]$ inulin from the vitreous humor in the rabbit eye. Data points show the mean for two eyes.

Figure 2. Depression of the retina's synthesis of $\left[{ }^{3} \mathrm{H}\right]$ phosphorylcholine by hemicholinium-3. Incubations were for $10 \mathrm{~min}$, and each point shows mean values for four retinas; standard errors were less than $10 \%$ of the means. 
in $56 \mathrm{mM}$ Veronal acetate buffer ( $\mathrm{pH} 7.8$ ) containing 130 $\mathrm{mM}$ sucrose and $1.8 \mathrm{~mm} \mathrm{CaCl}_{2}$. All animals were killed in the middle of the 12:12 light:dark cycle, near midday.

Light microscope sections were cut at 1 to $2 \mu \mathrm{m}$ and stained with toluidine blue. For each retina examined, tissue was sampled from 35 to 70 different regions. Most sections photographed came from the visual streak or slightly ventral to it (central retina). Electron microscope sections were counterstained with lead and examined in a Philips 200 microscope.

A total of more than 100 eyes were examined following $\mathrm{HC}-3$ injection, at times varying from $12 \mathrm{hr}$ to 156 days after the injection. At least three eyes were studied at each time point described in the text.

In vitro experiments. For studies in which retina was incubated in vitro, the eye was quickly removed following anesthesia and was hemisected. The posterior eyecup was transferred to an incubating medium and everted over the end of a Teflon rod. The retina was gently teased from the pigment epithelium and transferred to a 6-ml "boat" (Geiman et al., 1946), which was maintained at $37^{\circ} \mathrm{C}$ by a water bath and gently rocked. Extensive precautions were taken to avoid contamination of the medium with possibly toxic substances. The oxygenatcd medium simulated cerebrospinal fluid in its electrolytes and contained (millimolar): $\mathrm{Na}^{+}, 143.0 ; \mathrm{K}^{+}, 3.6 ; \mathrm{Ca}^{++}$, $1.15 ; \mathrm{Mg}^{++}, 1.2 ; \mathrm{Cl}^{-}, 125.4 ; \mathrm{HCO}_{3}^{-}, 22.6 ; \mathrm{H}_{2} \mathrm{PO}_{4}^{-}, 0.1$; $\mathrm{HPO}_{4}{ }^{=}, 0.4 ; \mathrm{SO}_{4}{ }^{-}, 1.2$; glucose, 10 . These methods are based on those of Ames and his colleagues. Previous evidence has shown that retinas incubated in this way maintain their morphological integrity, protein synthesis, glucose and oxygen metabolism, neurotransmitter synthesis and release, ganglion cell electrophysiological activity, and photoreceptor cell sensitivity for many hours (Ames and Hastings, 1956; Ames and Pollen, 1969; Masland and Ames, 1976; Masland and Livingstone, 1976; Masland and Mills, 1979; Ames and Nesbett, 1981).

The synthesis of radioactive phosphorylcholine and acetylcholine from exogenous choline was evaluated by high voltage electrophoresis of tissue extracts after incubation with radioactive choline. The retinas were isolated and pre-incubated for $10 \mathrm{~min}$ in control medium, after which they were transferred to medium containing $5 \mu \mathrm{M}\left[{ }^{3} \mathrm{H}\right]$ choline $(4.8 \mathrm{Ci} / \mathrm{mmol}$, New England Nuclear) for $10 \mathrm{~min}$. They were then removed, weighed, and homogenized in formate-acetate buffer at $\mathrm{pH} 2$. The homogenate was centrifuged at $6000 \times g$ for $20 \mathrm{~min}$, and 20 $\mu \mathrm{l}$ of the supernatant were spotted on Whatman $3 \mathrm{M}$ paper. After electrophoresis in the same buffer for $2 \mathrm{hr}$ at $3000 \mathrm{~V}$, the paper was cut into strips, eluted into $1 \mathrm{ml}$ of $\mathrm{H}_{2} \mathrm{O}$, and counted by standard methods.

For recording of the electroretinogram, the isolated retina was spread out, photoreceptor cells up, in a 1.5$\mathrm{ml}$ incubation chamber and was superfused with medium at $1.5 \mathrm{ml} / \mathrm{min}$. The recording electrodes were $0.5-\mathrm{mm}$ diameter polyethylene tubes filled with $5 \%$ agar in 150 $\mathrm{mM} \mathrm{NaCl}$ and connected to a DC-coupled differential amplifier by chlorided silver wires. One electrode entered the chamber from the side; its tip was located beneath the tissue. The other electrode's tip was placed above the tissue.

Photic stimuli were generated by a $100-\mathrm{W}$ tungsten filament bulb (nominal color temperature $2975^{\circ} \mathrm{K}$ ) filtered by the heat filter of a Minolta slide projector and by an additional Ealing No. 26-3053 infrared absorber. Light from this source was collected by a parabolic reflector and collimating lenses and was directed to the recording chamber (whole field illumination) by mirrors. Stimulus timing was controlled by an electromagnetic shutter and intensity by neutral density step filters and wedges. Intensities given in the text refer to the illuminance measured at the surface of the incubating chamber by an SEI photometer. An unknown error is introduced by reflection at the air-medium interface and by internal reflections within the chamber, but for the present purposes this error seems insignificantly small.

The activity of single ganglion cells was recorded by Teflon-coated platinum-iridium electrodes. The isolated retina was positioned with the ganglion cells up in the same chamber in which the electroretinogram was recorded. The edges of the retina were held down by a platinum ring which served as a weight. The center of the retina was gently supported by an inflatable silastic dome, which stabilized the tissue for extracellular recording (Ames and Pollen, 1969). Photic stimulation of the retina was accomplished by a two-channel optical system that used the light sources and controls described above. At its final stage, light was directed into the reversed optics of a binocular microscope, by which means light or dark spots or anuli from 10 to $2500 \mu \mathrm{m}$ in diameter could be focused on the tissue. The stimuli could be moved to any point within a $2500-\mu \mathrm{m}$ diameter circle in the retina, or swept across it, by rack and pinion drives. The position of the stimuli was monitored before demagnification by a pointer referred to a stationary $\mathrm{x}$-y grid, which provided visible coordinates for reference during plotting of receptive fields.

Previous work has shown that the electrophysiological activity of these preparations is stable for as long as 52 hr (Ames and Nesbetl, 1981). In the present experiments, the electroretinogram and the activity of single ganglion cells were stable from the beginning of the experiment to the end, the longest experiment lasting about $7 \mathrm{hr}$.

The methods of isolating the retina, incubation in vitro, analysis of choline metabolites, and electrophysiological study have been described in more detail in previous publications (Masland and Ames, 1976; Masland and Mills, 1979).

\section{Results}

We began by studying the effect of hemicholinium-3 on the retina in vitro, in order to obtain an indication of the degree to which phospholipid synthesis might be influenced by the drug. To simulate the conditions that occur in vivo, retinas were incubated in medium containing $\left[{ }^{3} \mathrm{H}\right]$ choline at $5 \mu \mathrm{M}$, the concentration thought to be present in the brain's extracellular spaces (Birks and MacIntosh, 1961). We measured the appearance in the tissue of $\left[{ }^{3} \mathrm{H}\right]$ phosphorylcholine, as an indication of the extent to which extracellular choline could enter the pathway leading to its incorporation into phosphatidylcholine. We found $\mathrm{HC}-3$ to depress the retina's synthesis of $\left[{ }^{3} \mathrm{H}\right]$ phosphorylcholine, with half-maximal inhibition occurring at $30 \mu \mathrm{M}$ (Fig. 2). 
Light microscopy. Parallel experiments were carried out in vivo, by injection of $\mathrm{HC}-3$ into the vitreous. This caused degeneration of the outer segments of both rods and cones. Injections were made over a wide concentration range (see below), but in the largest series of experiments (56 retinas) $17.9 \mu \mathrm{g}$ of $\mathrm{HC}-3$ were injected, which yielded an intraocular concentration of approximately 20 $\mu \mathrm{M}$. Unless otherwise specified, the descriptions that follow refer to events following a single intravitreal injection at that concentration. The effects on rods will be described first.

Abnormality of the rod outer segments was first seen by light microscopy as a region at their base that stained lightly with toluidine blue and appeared 1 to 2 days after hemicholinium-3 injection. The lightly staining region then expanded and was more readily discernible as the outer segments began to shorten (Fig. 3). At this stage, the outer segments were apparently fragile and often detached during processing. (The retinas do not appear to have been separated from the pigment epithelium in vivo. When eyes were removed from living animals for physiological studies, the retina was found to have remained tightly apposed to the back of the eye, and gentle scraping was required to separate it.) Between 2 and 5 days after HC-3 injection, the distal, normally staining portion of the outer segment detached and was phagocytosed by the pigment epithelium. The shed portion of the outer segment was rapidly engulfed by the pigment epithelium. Digestion by the pigment epithelium oc- curred with surprising speed. However, in favorable cases a dramatic accumulation of large phagosomes was visible. Phagosomes of this size and number were never observed in normal animals. They are illustrated in Figure 3 (right). The rod inner segments then began to shorten. Between 10 and 14 days after $\mathrm{HC}-3$ injection, outer segments were missing from all rods, and the inner segments were substantially reduced in length (Fig. 4).

The only other effect observable in light microscopy was degeneration of a small, distinct group of neurons in the inner nuclear layer. This degeneration, which always occurred following high dose (greater than $500 \mu \mathrm{M}$ ) injections, was occasionally seen after injection of the standard $20 \mu \mathrm{M}$ dose. The affected cells apparently swell and lyse; within 2 days after injection of $\mathrm{HC}-3$, their nuclei were surrounded by a shell of empty space (Fig. 5). They were spaced regularly along the inner margin of the layer, making up less than $2 \%$ of the total cells of the layer. From their location and spacing, it seems quite possible that these are the acetylcholine-synthesizing amacrine cells (Masland and Mills, 1979), which would be expected to be vulnerable to $\mathrm{HC}-3$ because of competition by choline acetyltransferase for the available intracellular choline. However, an equal number of acetylcholinesynthesizing amacrines is known to be located in the ganglion cell layer (Hayden et al., 1980), and we did not observe damaged cells there. In an attempt to evaluate the situation biochemically, we isolated retinas 2 weeks after injection of $2 \mathrm{mM} \mathrm{HC}-3$, rinsed them thoroughly,
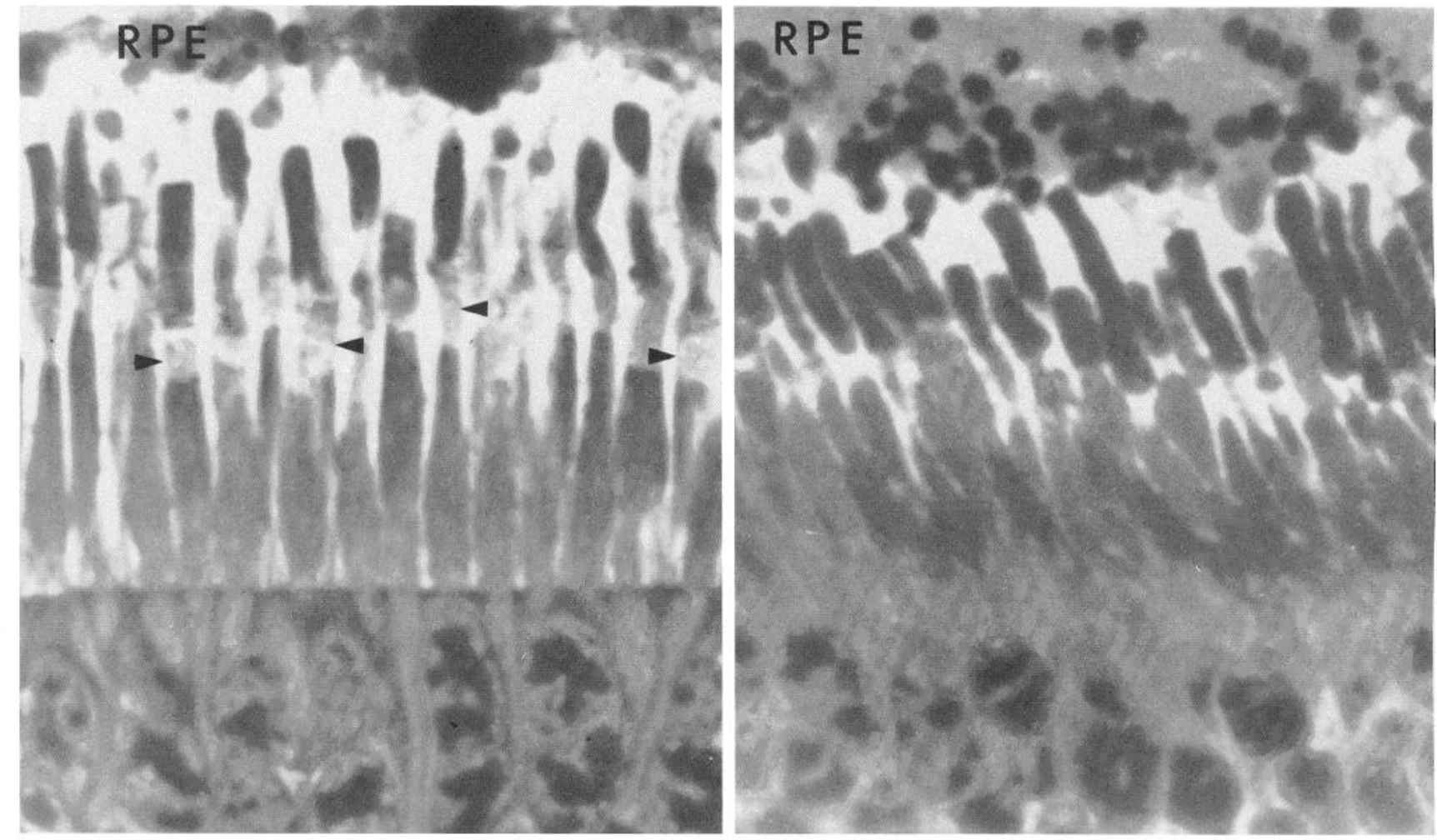

Figure 3. Light micrographs from two different regions of the same retina on the second day after exposure to $20 \mu \mathrm{M}$ Left, The basal portions of the rod outer segments (arrowheads) stain lightly and appear disrupted. Right, Example of an instance where the pigment epithelium contains a large accumulation of phagosomes. Magnification $\times 1500$. RPE, retinal pigment epithelium. 

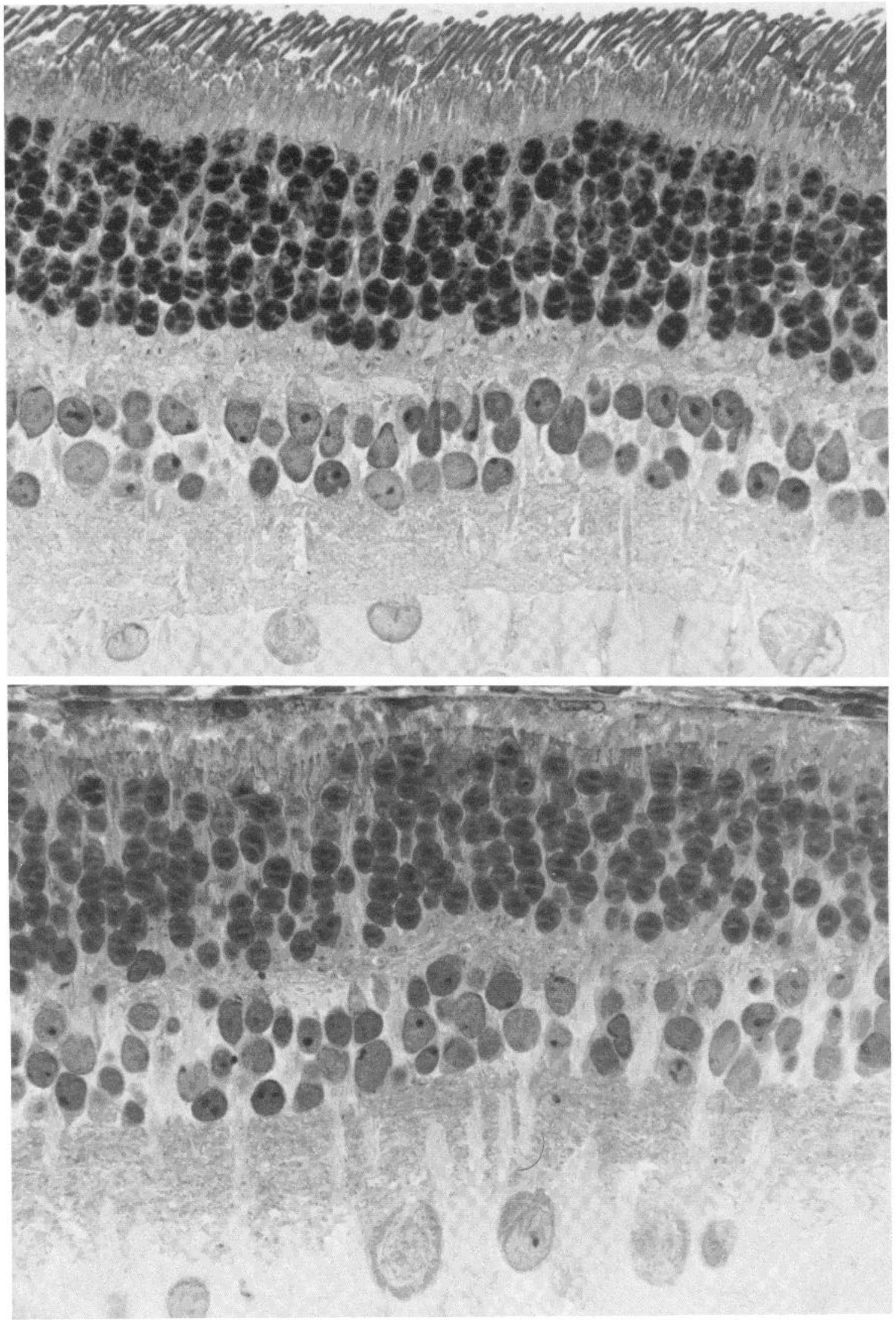

Figure 4. Retinas 2 weeks after control injection (top) or exposure to $20 \mu \mathrm{M} \mathrm{HC}-3$ (bottom). Loss of the outer segments following HC-3 exposure is the only obvious difference between the sections. Part of the pigment epithelium detached from the control retina during processing. Both retinas were fixed by direct osmium immersion. Magnification $\times 600$. 

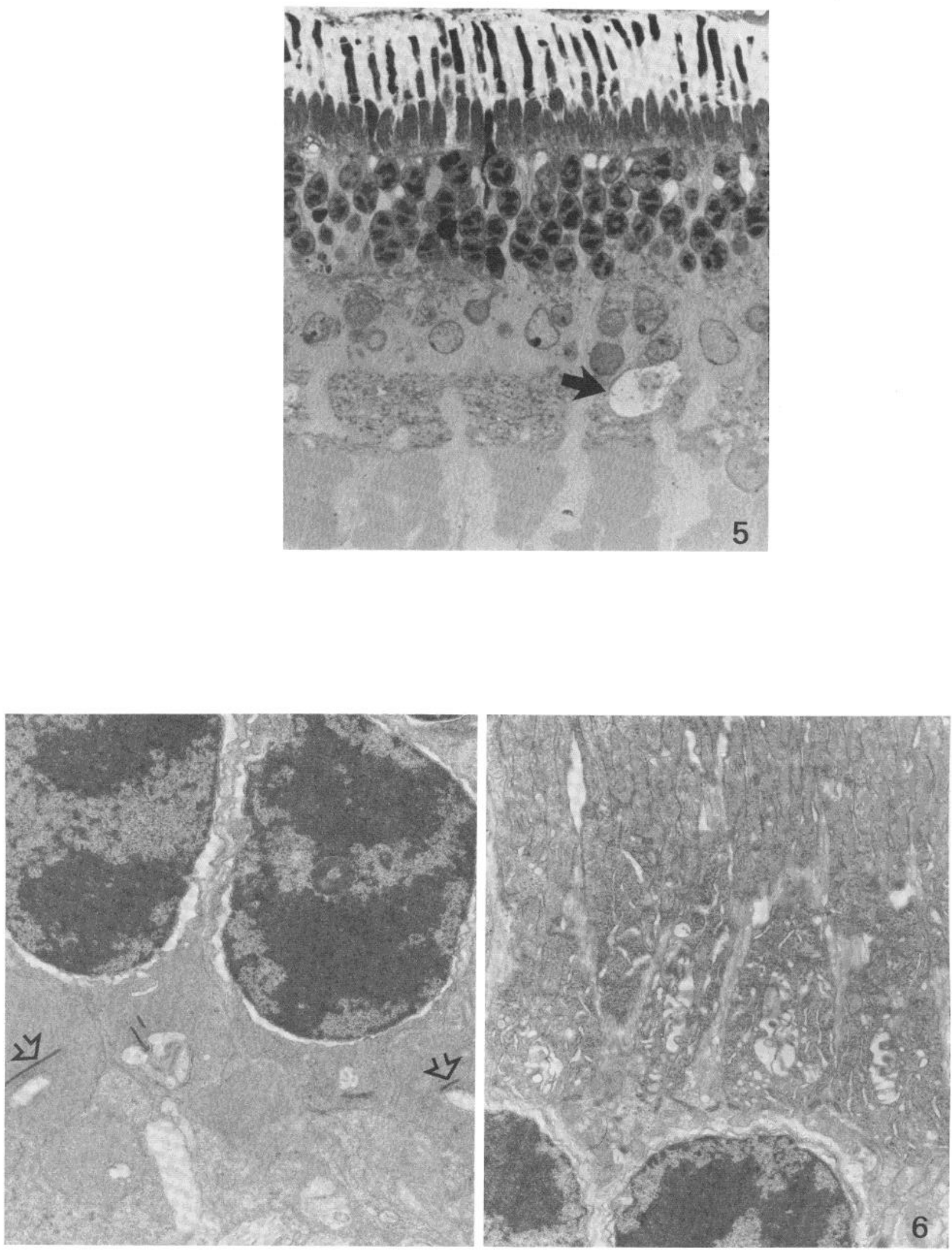

Figure 5. Selective loss of cells adjacent to the inner nuclear layer $24 \mathrm{hr}$ after $1000 \mu \mathrm{M} \mathrm{HC}-3$ injection. A sparsely distributed group of cells was destroyed; one such cell is pointed out (arrow). The location and spacing of these necrotic cells suggest they are the acetylcholine-synthesizing amacrine cells. Rod and cone outer segments also show damage; the cone nuclei and inner segments appear heavily damaged as well. Magnification $\times 500$.

Figure 6. Retina 1 day after exposure to $20 \mu \mathrm{M} \mathrm{HC}-3$ Left, Swollen nuclear envelope of photoreceptor cell. Note the normal synaptic terminal with synaptic ribbons (arrows). Right, Distal portion of photoreceptor perikaryon, showing swollen nuclear envelope and endoplasmic reticulum. Magnification $\times 5700$. 
and incubated them in the presence of $\left[{ }^{3} \mathrm{H}\right]$ choline. Using methods identical to those described above for measurement of $\left[{ }^{3} \mathrm{H}\right]$ phosphorylcholine, we found the retina's synthesis of $\left[{ }^{3} \mathrm{H}\right]$ acetylcholine to be reduced by $58 \%$. Although we do not understand why one group of cholinergic neurons would be more sensitive to $\mathrm{HC}-3$ than the other, this result is consistent with damage to about half of the acetylcholine-synthesizing amacrine cells.

Electron microscopy. The first fine-structural change induced by HC-3 was a dilation of the nuclear envelope and endoplasmic reticulum, seen less than a day after drug injection in all retinal cells (Fig. 6). The swelling of these organelles (the sites of phospholipid synthesis) disappeared within a week. Similar swelling was also described by Osborne and Monaghan (1976) in the clawed toad retina soon after intraperitoneal injection of hemicholinium-3.

Shortly after the appearance of nuclear envelope swelling, the number of round, 100- to $200-\mathrm{nm}$ vesicles in the ellipsoid and myoid regions increased. A few such vesicles are a regular feature of control retinas, but, in the HC3 -treated retinas, there was a small but unmistakable proliferation of them. While the vesicles in control retinas are usually isolated, in treated retinas they commonly appeared in small groups and frequently accumulated in the periciliary cytoplasm (Fig. 7).

Rows of 50- to $100-\mathrm{nm}$ round vesicles then appeared at the base of the rod outer segment (Fig. 8). The region of vesicles corresponded to the lightly staining region seen by light microscopy. Sometimes there was only one row of basal vesicles, but more commonly several rows were seen. They lined up horizontally, commonly spanning the width of the outer segment. Rows of vesicles interleaved with groups of normal discs were often observed. Isolated small groups of vesicles occasionally extended up the plasma membrane to lie alongside otherwise normal-appearing discs. They were never seen in control retinas. In isolated instances, vesicles were absent from the outer segment, and HC-3 exposure instead induced the formation of stacks of discs which were misoriented by $90^{\circ}$. Despite these abnormalities at the rod outer segment base, the distal portion of the outer segment appeared to have normal structure. On the first day after the HC-3 injection, normal regions occupied more than $90 \%$ of the outer segment length.

By the third day after HC-3 injection, the basal region of vesicles comprised 20 to $70 \%$ of the outer segment. The size of the vesicles had expanded to 300 to $1000 \mathrm{~nm}$ (Fig. 9). The attachment of the outer segment to the pigment epithelium was very fragile at this time, but, even when the retina detached during processing, photoreceptor soma remained intact. The pigment epithelium had already begun digesting the remaining outer segment discs. Within 7 days, outer segments were absent from the retina.

After loss of the outer segment, a major reduction in the length of the inner segment followed. The amount of endoplasmic reticulum decreased by more than half. More than $75 \%$ of the mitochondria degenerated, and lysosomes became more prominent. The inner segments gradually shortened (Fig. 10). Their final length was variable. In some regions they were essentially elimi-

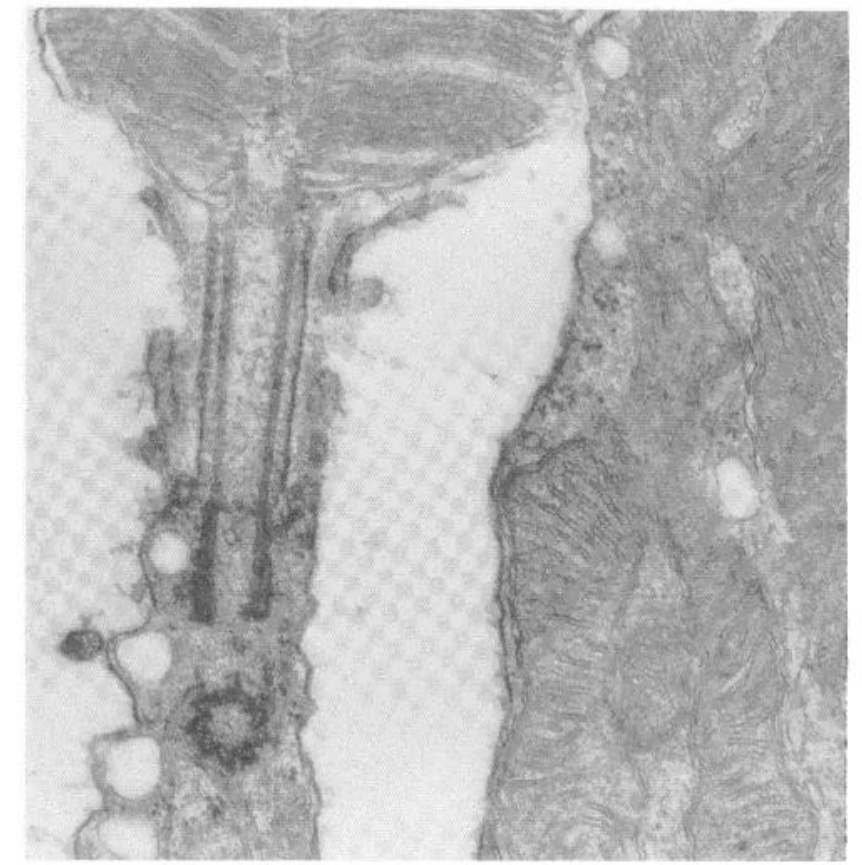

Figure 7. Periciliary region of rod photoreceptor cell on the first day after exposure to $20 \mu \mathrm{M} \mathrm{HC}-3$. An increased number of round vesicles, about $100 \mathrm{~nm}$ in diameter, is present. Magnification $\times 22,500$.

nated; a span of cytoplasm of only $2 \mu \mathrm{m}$ separated the edge of the photoreceptor nucleus from the border of the pigment epithelium. In other cases as much as half of the inner segment survived. The average was roughly $25 \%$ of the original outer segment length.

By 14 days after $\mathrm{HC}-3$ injection, the inner segments had stabilized. At this time the surviving inner segment organelles appeared normal. The other portions of the photoreceptor cell, including the synaptic region and structures associated with the connecting cilium, also survived. Both plexiform layers were well preserved, and synapses were commonly seen throughout the retina (Fig. 11).

Regeneration. Fourteen days after a single injection of $\mathrm{HC}-3$, its concentration in the vitreous had fallen well below the threshold at which outer segment damage is caused (see "Materials and Methods" and the dose dependence described below). During subsequent weeks, the structure of most photoreceptor cells remained stable, and some slowly began to regenerate an outer segment. The first unequivocal sign of regeneration was stacks of 20 to 100 discs seen in scattered retinal regions about 20 days after injection. These outer segments were frequently irregular in outline, because their sides were not parallel (i.e., their discs were of unequal diameter). Many misoriented basal discs were present (Fig. 12). The outer segments continued to elongate slowly. By day 40 after the injection, some rods contained as many as 350 discs; their outer segments had the normal cylindrical shape and were about half the normal length. Even though outer segments never reached full length, phagosomes were seen in the pigment epithelium at all times examined. The relationship of the regenerated outer segments and pigment epithelium was more complex 
than normal. Instead of a single process wrapping the outer segment, often several were observed. This morphology is normally seen with cone, but not with rod outer segments (Bunt, 1978).

Regeneration of the outer segments was more variable than the initial lesion, and there were always regions where it did not occur. In some regions the cell bodies appeared normal, and all photoreceptor cells were apparently regenerating their outer segments. At the other extreme, some regions showed unequivocal photoreceptor cell death, thinning of the outer nuclear layer, and Müller cell hypertrophy. The ventral region of the retina generally recovered better from the injection than the dorsal. This global variability may have been due to uneven exposure of the retina to the drug following intraocular injection. Variable regeneration also occurred at a local level. Groups of regenerating rods were commonly interspersed amongst photoreceptor cells without outer segments, as observed in serial light microscopic sections. It seems likely that many of the cells that do not regenerate an outer segment eventually die. The local variability in regeneration became more striking with time.

Cone degeneration. Cones were more sensitive to $\mathrm{HC}$ 3 damage than rods, and the degeneration of their outer segments proceeded differently. As in rods, the first morphological events after $\mathrm{HC}-3$ injection were swelling of the nuclear envelope and endoplasmic reticulum plus appearance of an increased number of inner segment vesicles. However, in cones there was never an accumulation of vesicles within the outer segment. Instead, pathology of the membranes appeared throughout its length. Disks disappeared from much of the outer segment. Membranous remnants and isolated stacks of disks persisted in scattered regions of the outer segment (Fig. 13). Accumulations of phagosomes were also commonly seen adjacent to degenerating cones. By day 2, HC-3 severely damaged all cones. Most ellipsoid mitochondria

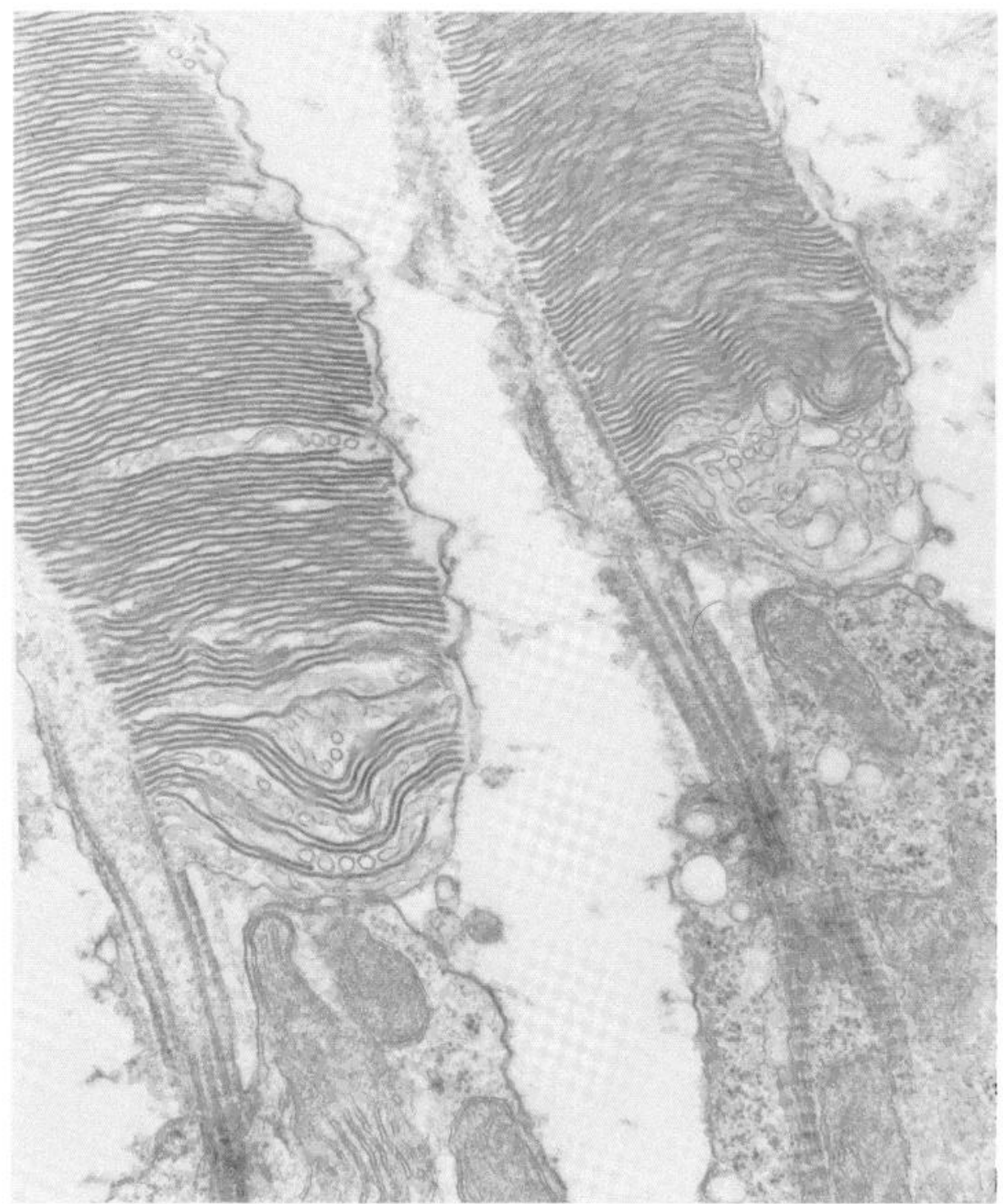

Figure 8. Basal portion of the rod outer segment on the first day after exposure to $\mathrm{HC}-3$. Round vesicles are seen interleaved among normal discs. Magnification $\times$ 41,000 . 

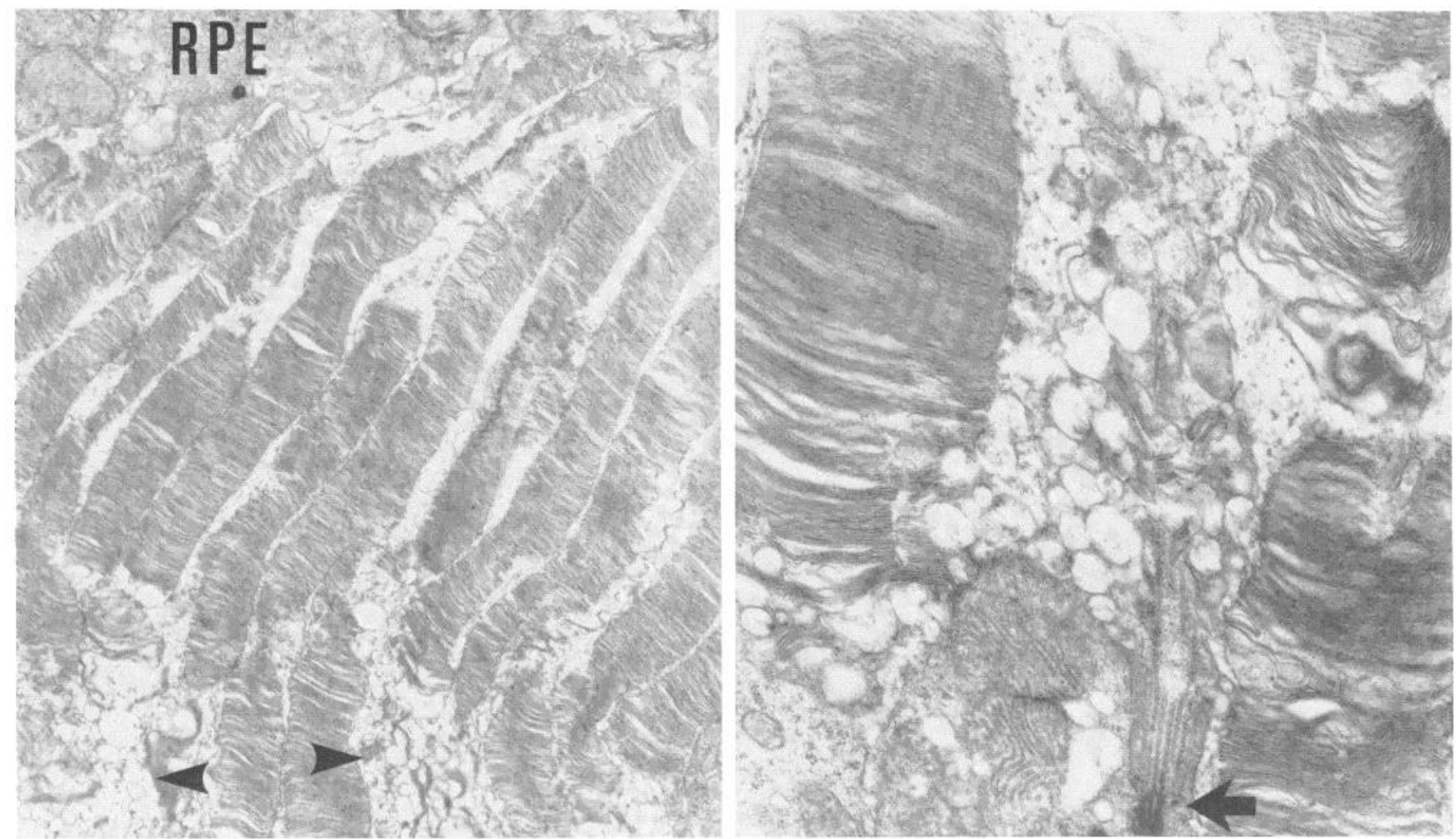

Figure 9. Retina 3 days after exposure to $20 \mu \mathrm{M}$ HC-3. Left, The basal part of the outer segment is filled by a mass of large round vesicles (arrowheads). This abnormal region may cover up to $70 \%$ of the remaining outer segment length. Magnification $\times 7000$. Right, The basal portion of another photoreceptor cell showing the base of the connecting cilium (arrow) and its distal extension. Magnification $\times 19,500$. $R P E$, retinal pigment epithelium.

were necrotic, and cone death soon followed. By day 7 , we could not find any cells containing the distinctive characteristics of either cone nuclei or synaptic terminals. Not surprisingly, we never saw cone outer segments during the regeneration studies. The great sensitivity of cones to $\mathrm{HC}-3$ is consistent with what appears to be a faster phosphatidylcholine turnover in cones than in rods, as evidenced by denser cone labeling in autoradiographs following exposure of the retina to radioactive fatty acid or choline (Bibb and Young, 1974; Masland and Mills, 1979).

Dose dependence. With the exception of the amacrine cell described above, retinal neurons other than the photoreceptors seemed rather little affected by HC-3. This was true at a wide range of $\mathrm{HC}-3$ concentrations. An initial intraocular concentration of $20 \mu \mathrm{M}$, at which most of our experiments were carried out, always destroyed the photoreceptor outer segments. Intraocular concentrations of $1 \mu \mathrm{M}$ or less never caused morphological damage to any retinal element. Concentrations between 5 and $20 \mu \mathrm{M}$ always caused some damage to rod outer segments, but their complete destruction was rare. These doses also caused damage to cones.

$\mathrm{HC}$-3-induced damage was restricted to the photoreceptor cells at concentrations substantially higher than threshold. In a series of 42 retinas studied at times varying up to 2 weeks after injections at initial concentrations from 40 to $5000 \mu \mathrm{M}$, it was not until the concentration exceeded $1000 \mu \mathrm{M}$ that retinal neurons other than the photoreceptors (and the small amacrine subset) be- gan to be damaged (Fig. 14). Even at $5000 \mu \mathrm{M}$ (a dose that kills most of the rabbits by neuromuscular blockade on the day of the injection, as HC-3 leaves the eye and enters the general circulation), the most severe lesion 2 weeks after treatment was to the photoreceptors; although there was cell loss in the inner nuclear and ganglion cell layers, all retinal layers remained easily identifiable.

Responses to light by retinas with hemicholinium-damaged outer segments. There was behavioral evidence that the retinas of $\mathrm{HC}$-3-injected eyes were not entirely unresponsive to light; a sudden exposure to an ophthalmic flashlight always caused the eye to blink. The eye closure was weak compared to responses by normal eyes and occurred with a latency of several seconds, but it was nonetheless unmistakable. It occurred at all times after injection of $\mathrm{HC}-3$. To evaluate the function of these retinas more directly, we recorded their electrical activity: the electroretinogram, as a way of assessing the responses of the photoreceptors; and the activity of single ganglion cells, to study the action of the retina's neural networks.

The electroretinogram was recorded from isolated retinas incubated in a flowing perfusate. The experiments began with the retina maintained in control medium, so that we could observe both the a-wave, which reflects the activity of the photoreceptor cells, and the b-wave, which is due to the synaptic activation of more proximal neurons by the photoreceptors (Brown and Wiesel, 1961). However, the latter potential occurs superimposed 

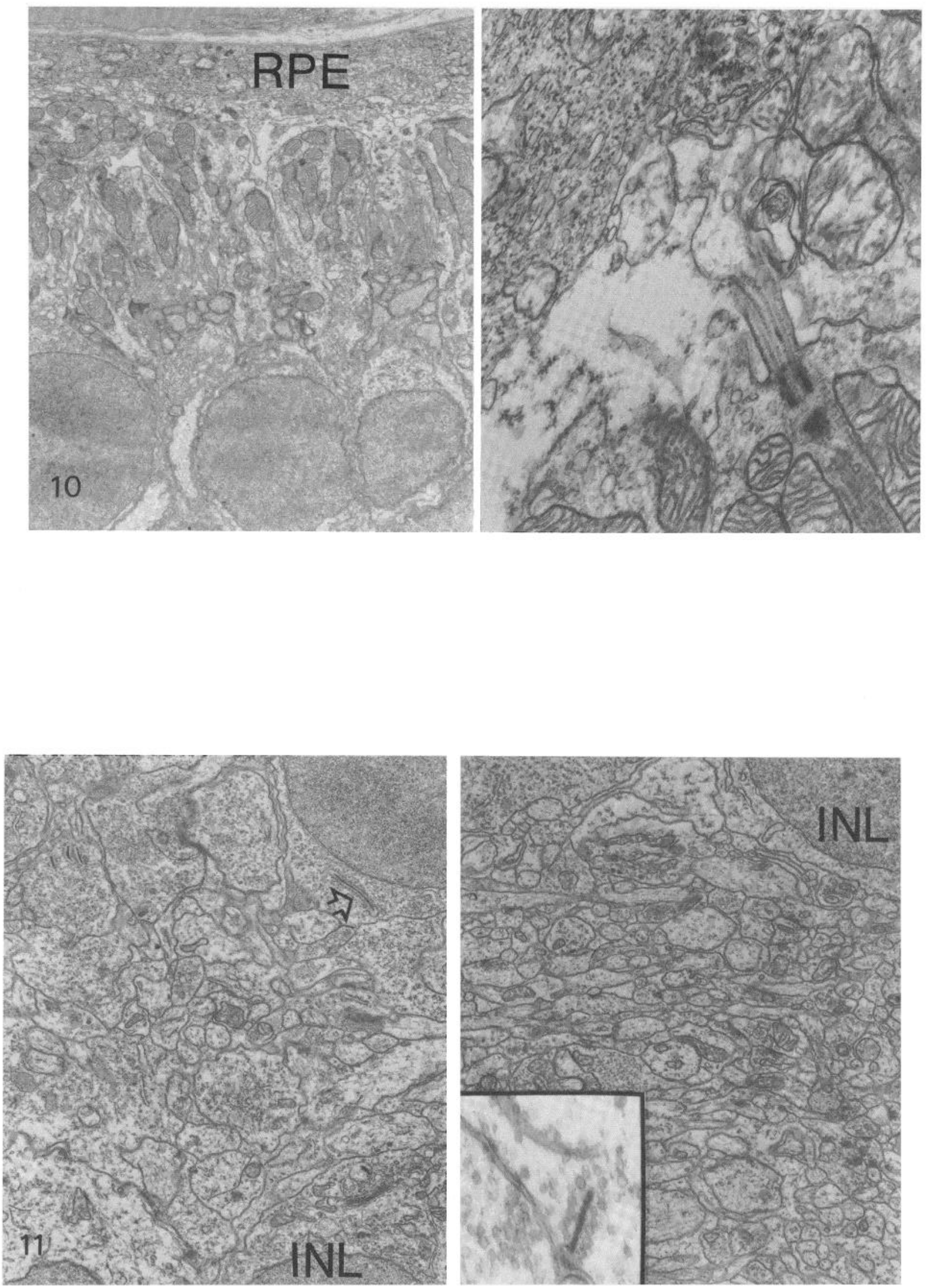

Figure 10. Retina 2 weeks after exposure to $20 \mu \mathrm{M} \mathrm{HC}-3$. Left, Loss of all outer segment material. The inner segment is reduced in size, but the remaining photoreceptor cell morphology is well preserved. Magnification $\times 3,300$. Right, Higher power of the ciliary region of a degenerated photoreceptor cell. Magnification $\times 30,000$. RPE, retinal pigment epithelium.

Figure 11. Synaptic regions 2 weeks after exposure to HC-3. Left, Outer plexiform layer showing several photoreceptor terminal synapses. Right, The inner plexiform layer also appears well preserved. The inset shows a bipolar cell terminal from this region. Magnification left and right, $\times 7000$; inset $\times 40,000 . I N L$, inner nuclear layer. 


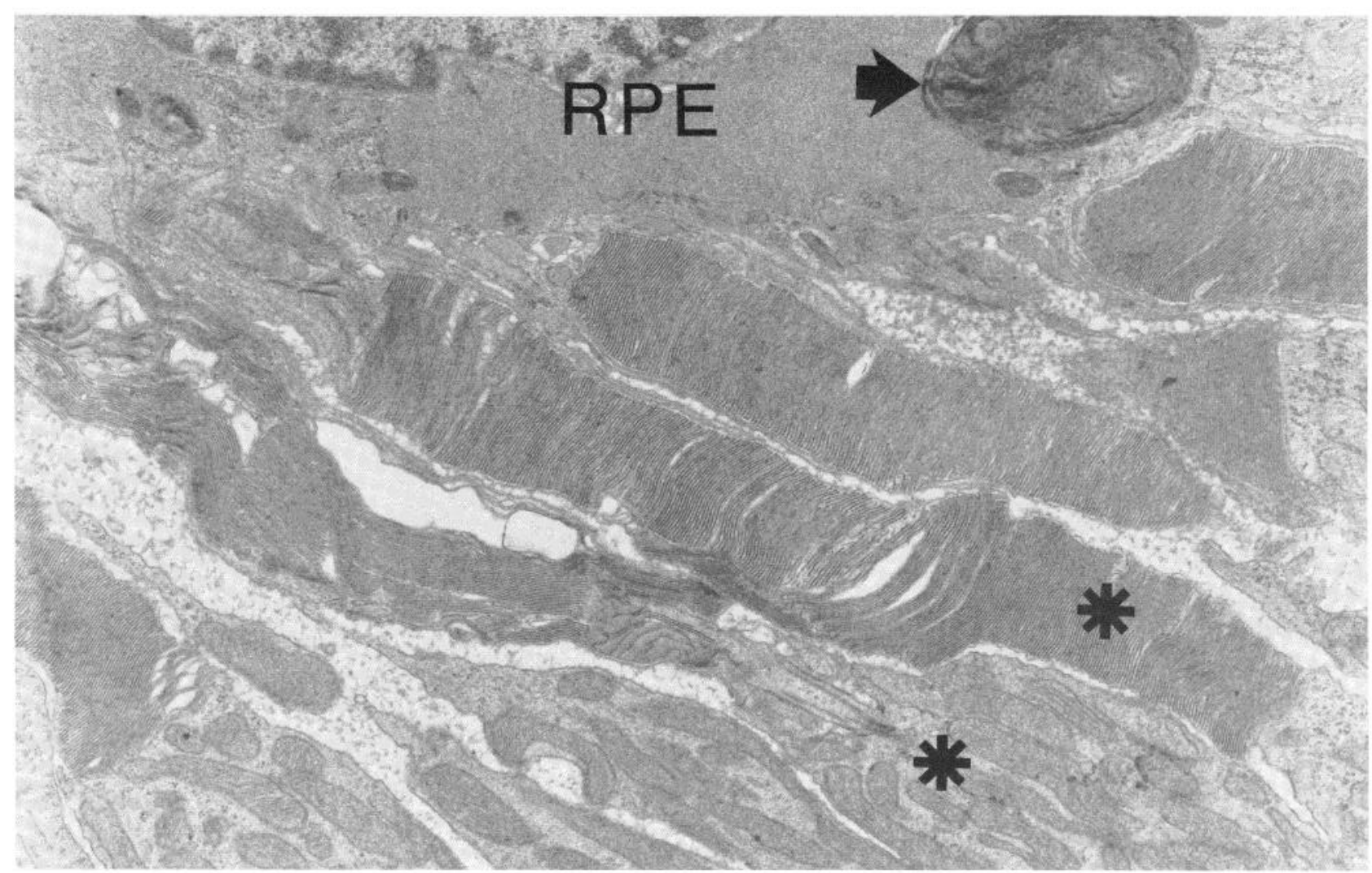

Figure 12. Regenerating rod outer segments in a retina 34 days after exposure to $20 \mu \mathrm{M} \mathrm{HC}-3$. The newly synthesized disks, which are often neatly stacked, vary in width. Consequently, the regenerated outer segment lacks the straight sides seen in normal cells. Note that the outer segments have "fallen over" and are oriented almost parallel to the pigment epithelium. Two cells $(*)$ contain disks misoriented by $90^{\circ}$. The pigment epithelium $(R P E)$ contains a large phagosome (arrow). Magnification $\times$ 13,000 .

on the a-wave and confounds attempts at quantitative study of the photoreceptor cell response. For that reason, after completing examination of the electroretinogram in control medium, we changed the perfusate to a medium containing $5 \mathrm{mM} \mathrm{Na}{ }^{+}$aspartate, which prevents neurotransmission from photoreceptor cells to the proximal neurons and thus isolates a response (PIII of the electroretinogram) that depends primarily on the activity of the receptors (Sillman et al., 1969). We found the waveform of the electroretinogram to be normal, with the exception of an unexplained notch regularly present on the falling phase of the b-wave (Fig. 15). As time elapsed after injection of $\mathrm{HC}-3$, the amplitude of all components of the response declined. Intensity-response functions were established for the isolated PIII at 2, 4, 8, 12, 21, and 40 days after injection of $\mathrm{HC}-3$. Twelve days after injection, no electroretinogram could be recorded, and, during the subsequent weeks, there was a gradual, partial recovery of the response (Fig. 16). These findings are in good accord with the morphological results described above.

Other retinas were isolated 6,14 , and 19 days after HC-3 injection and were incubated for microelectrode recording from the ganglion cells. These recordings could be compared with those obtained from two normal retinas (and with a series of about 150 normal retinas studied previously, using identical methods; Masland and Ames, 1976). In all of the $\mathrm{HC}-3$-injected retinas, action poten-

Figure 13. Cone degeneration on the first day after exposure to $20 \mu \mathrm{M} \mathrm{HC}-3$. Two degenerating cones (*) are adjacent to a region of rods which have vesicles at the base of the outer segment. Cone outer segments always degenerated simultaneously along their entire length. Magnification $\times 5000$.

Figure 14. Retina 2 weeks after exposure to $1000 \mu \mathrm{M}$ HC-3. As with the standard $20 \mu \mathrm{M}$ dose, the major effect of HC-3 is to destroy outer segments. However, with the higher dose, there is also loss of retinal neurons. Magnification $\times 500$.

Figure 15. Electroretinograms recorded from a normal retina and a retina studied 8 days after injection of HC-3. Each retina was studied first during incubation under normal conditions, and later during incubation in the presence of 5 mM sodium aspartate, which isolated the contribution of the photoreceptor cells. Although the amplitudes of the responses of the HC-3treated retina were very much reduced (note changes in amplification), their latency and fundamental waveform were very similar to normal. Stimulus duration was $100 \mathrm{msec}$ for all traces. Stimulus intensity for both aspartate-treated cases was 1.5 log foot-candles, as was the intensity for the HC-3-treated retina in control medium. For normal retinas stimulated by bright flashes, the large a-wave distorts the b-wave; in order to illustrate the shape of the b-wave in control medium, a much dimmer flash $(-2.0 \log$ foot-candles) was used. 

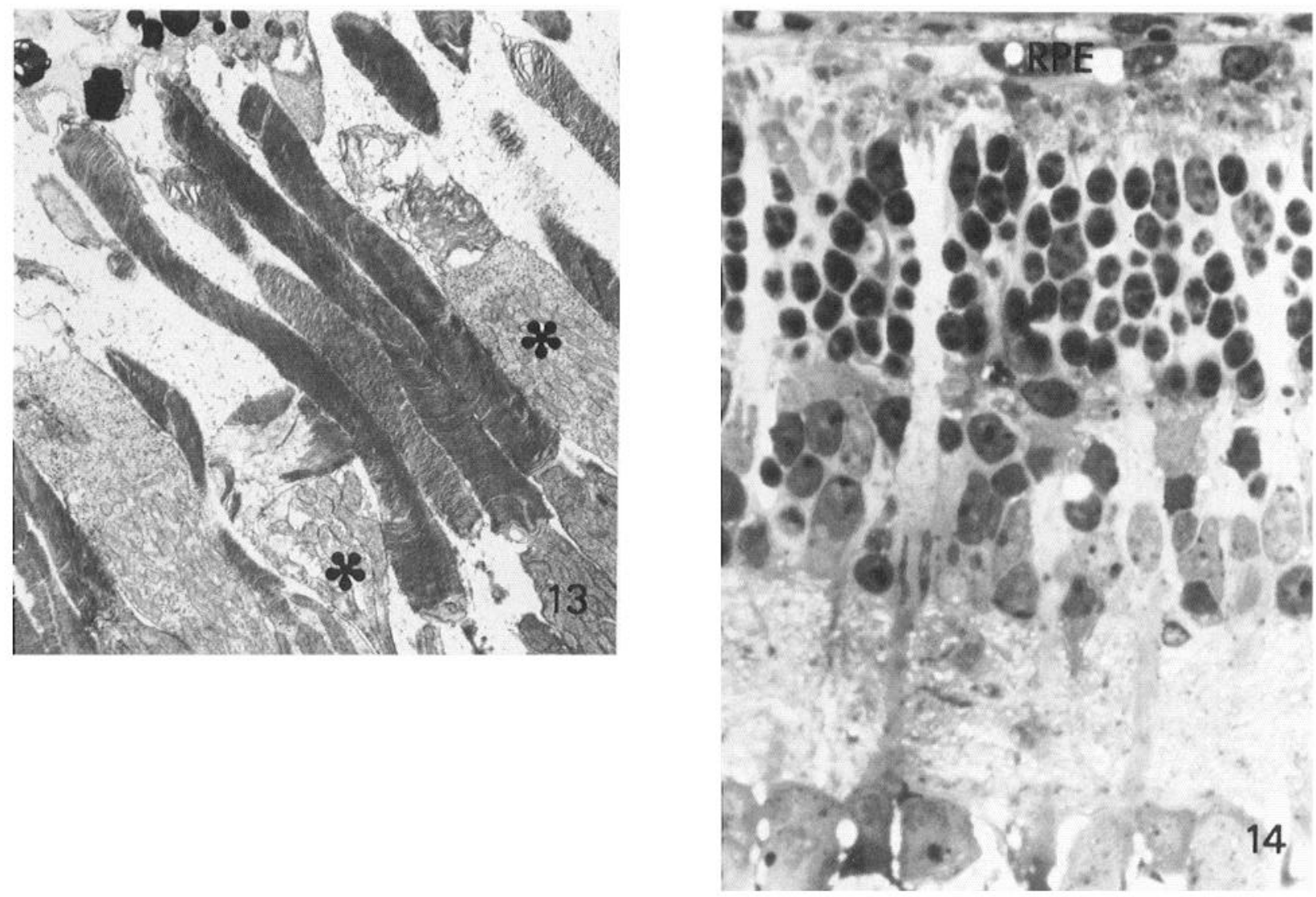

Normal

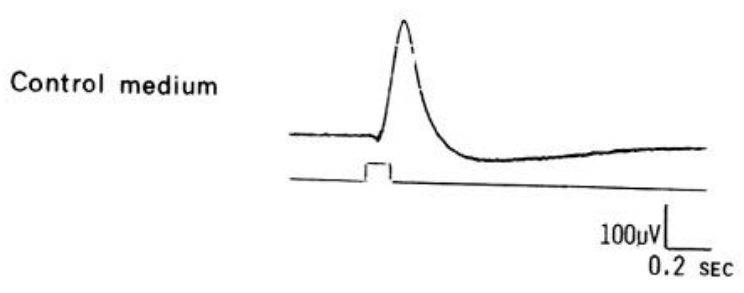

Aspartate-isolated P III

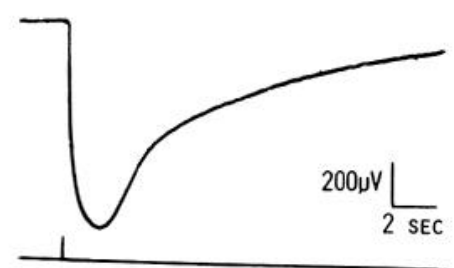

Hemicholinium -3
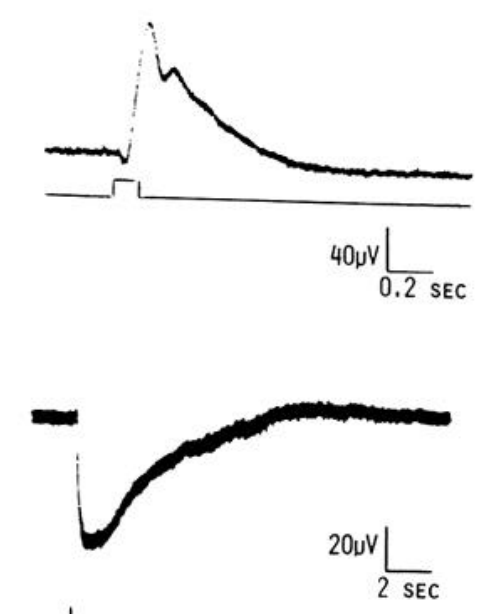

Figures 13 to 15 
tials were encountered at almost cvery touching of the electrode to the retina's surface; the number of active ganglion cells present thus appeared to be normal. The amplitude and shape of the action potentials likewise

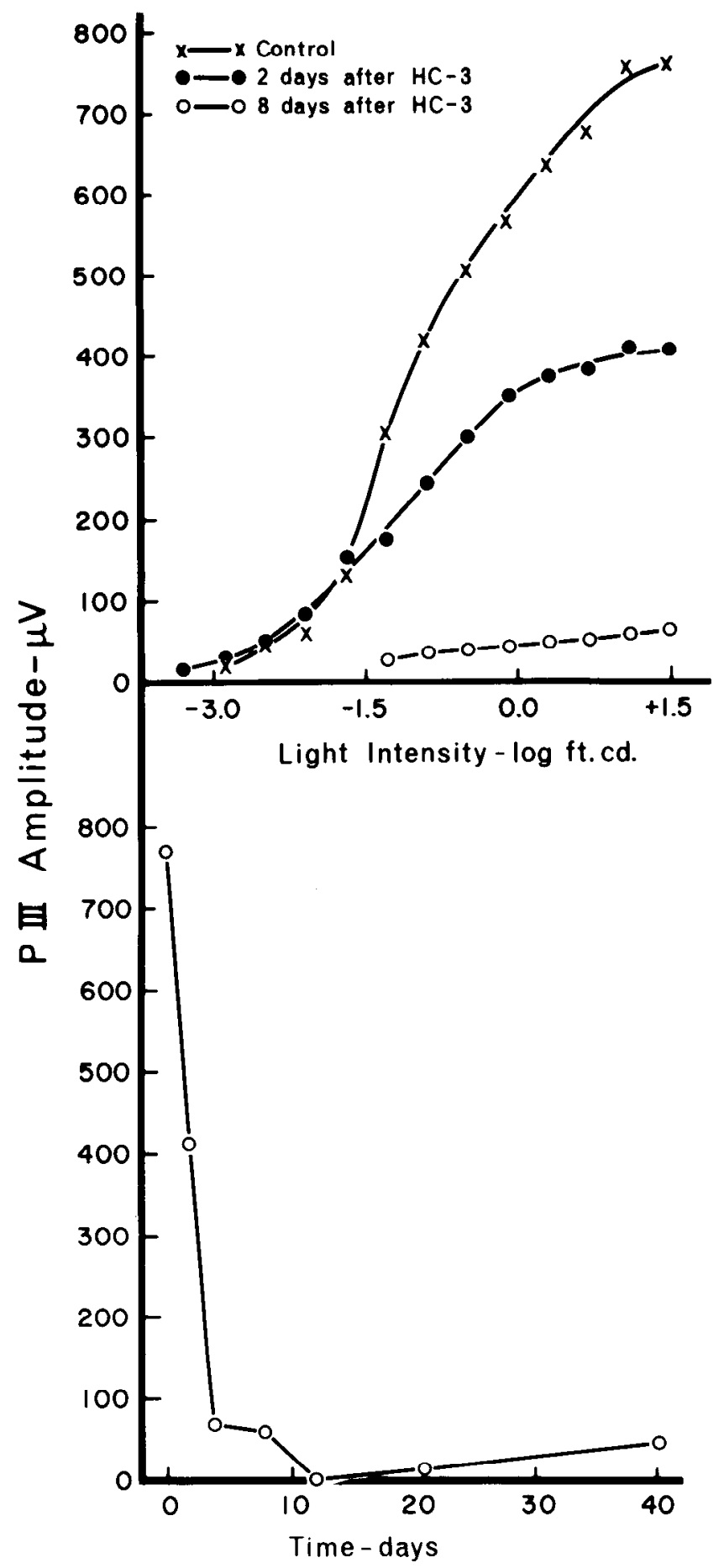

Figure 16. Top, Amplitude of the isolated photoreceptor cell response for a normal retina and at two times following injection of HC-3. Stimulus duration was $100 \mathrm{msec}$. Amplitude of the response was measured from base line to its peak negativity. Bottom, Response to our brightest (1.5 log foot-candles) flash at varying times after $\mathrm{HC}-3$ injection. Note the gradual recovery of the response at the longer times. Each point shows averaged responses from two retinas. were indistinguishable from control. Most of the cells encountered were spontaneously active in the dark, and, although systematic measurements were not made, it was clear that the rates of unstimulated firing by these neurons were not grossly different from those encountered in untreated retinas.

Of 54 cells studied in the $\mathrm{HC}$-3-treated retinas, all but 4 responded to light. However, it was immediately apparent that their sensitivity was enormously depressed. To estimate the magnitude of the depression, we devised a simple way to measure their thresholds. A spot 2500 $\mu \mathrm{m}$ in diameter was centered on the electrode and flashed for $500 \mathrm{msec}$, and stimulus intensity was varied in small steps by means of a continuous neutral density wedge. The response evoked was displayed on a storage oscilloscope, and an estimate was made of the point at which a barely detectable response was evoked; for most cells this meant a response of three to five action potentials above the background firing. Thresholds measured by this method were reproducible to within about $0.2 \log$ unit, a precision more than adequate to delineate the large changes in sensitivity observed (Fig. 17). Six days after injection of $\mathrm{HC}-3$, the threshold of the average ganglion cell was $3.3 \mathrm{log}$ units above normal. There was a slight additional increase in threshold at 14 days. By 19 days regeneration had begun, and the thresholds began to fall. As would be expected from the variability of regeneration observed morphologically, the thresholds of ganglion cells at 19 days were distributed across a wide range.

We were surprised to find responses by the ganglion cells 6 and 14 days after HC-3 injection. At 6 days the proximal portion of the outer segment has been replaced by what amounts to debris (Fig. 9), and at 14 days not only were the outer segments gone, but the inner segments were substantially shrunken, Therefore, we undertook a systematic inspection of all of the retinas prepared for morphological study at 14 days, on the chance that a few outer segments might have escaped our initial attention. Eight retinas had been harvested 14 days after $\mathrm{HC}-3$ injection. To survey the whole retinal area, different regions from each of these retinas had been embedded for electron microscopy in over 300 Epon blocks. Light microscopic inspection of sections from these blocks (223 linear $\mathrm{mm}$ of retina) revealed no evidence of outer segment material.

We also studied the receptive fields of the ganglion cells. Testing of their response properties was done by conventional mapping techniques; these included stimulation of the central excitable region with spots of varying sizes, evaluation of the effects of stimulation on the surrounding region, and testing of the response to light or dark spots swept across the receptive field. All ganglion cells in the $\mathrm{HC}$-3-treated retinas had definable receptive field areas, and the sizes of these areas appeared similar to those in normal retinas. To evaluate the more complex receptive field properties was not always possible because of the very bright light required to excite the cells. (At 6 and 14 days after HC-3 injection, many of the ganglion cell thresholds were near the upper limit of our stimulator.) While brief flashes were effective for these neurons, the steady light required for probing of their receptive field with moving stimuli often quickly 


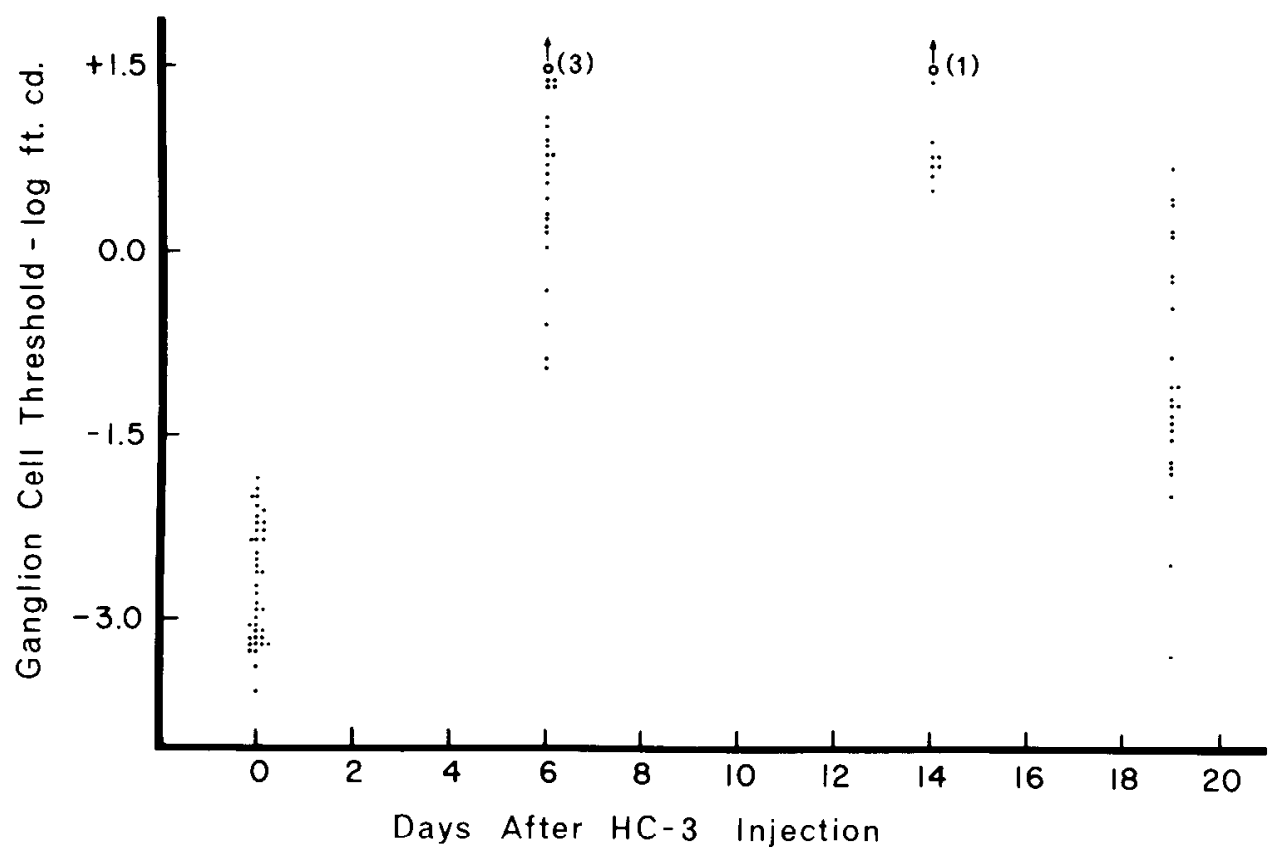

Figure 17. Response thresholds of single ganglion cells after $\mathrm{HC}-3$ injection. Four cells encountered 6 or 14 days after HC-3 injection did not respond to our brightest $(1.5 \mathrm{log}$ foot-candles) stimulus. These cells were located near cells whose requirements nearly exceeded the capability of the stimulator; they are indicated by arrows.

lost its ability to excite the cell; since movement is often the better stimulus for receptive field classification, such cells could not be studied well. For the more sensitive cells, however, this was not a problem, and in these cases normal receptive fields were encountered. Center-surround antagonism was easily demonstrated, as was directional selectivity. An example from a retina studied 19 days after HC-3 injection is shown in Figure 18. Thus, the responses of the ganglion cells are as would be expected of a retina that has suffered primarily an outer segment lesion; neurotransmilter release by the photoreceptor cells, and the inner retina's neural circuits, appear functional.

Controls. Ten-microliter saline or distilled water injections did not affect the retina, nor did choline itself, injected intraocularly at concentrations up to $10 \mathrm{mM}$.

Contamination of commercially available HC-3 by $N, N$-dimethyl-aminoethanol (deanol) has been reported (Jenden et al., 1977). At high concentrations (10 mM), deanol damaged the retina, but the damage was global and showed none of the fine-structural characteristics of the lesion caused by HC-3 injection.

The essential effects of HC-3 injection were the same in New Zealand Red rabbits, which have pigmented eyes, as in the albino rabbits on which most experiments were performed. Maintaining albino rabbits in the dark after injection also failed to change the fundamental results. The lesion was slightly reduced in both cases, in accord with the photoreceptor cell stress known to be caused by illumination (Lanum, 1978).

\section{Discussion}

Exposure of the retina to $\mathrm{HC}-3$ caused a lesion which began at the base of the rod outer segment and eventually destroyed it (Fig. 19). With the exception of a small and
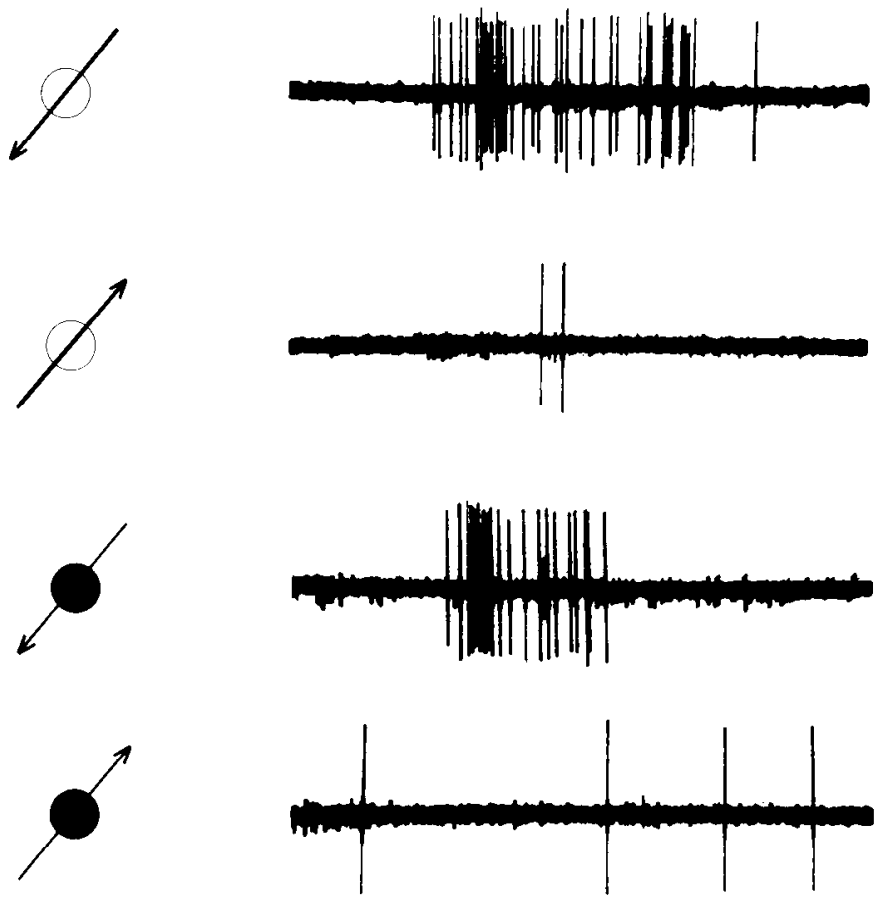

Figure 18. Directionally selective ganglion cell encountered in a retina studied 19 days after injection of $\mathrm{HC}-3$. Stimulus was a $250-\mu \mathrm{m}$ spot focused on the retina. The cell fired in response to the spot's motion across the retina in one direction (downward and to the left in the figure) and did not respond to motion in the opposite direction. The directional preference was the same for a bright spot moving on a dark background as for a light spot moving on a dark background. The threshold for a response of this cell to a diffuse light flash was $1.1 \mathrm{log}$ foot-candle indicating a partial recovery from $\mathrm{HC}-3$, but it was still almost 10 times less sensitive than the least sensitive cell encountered in the control sample. 
discrete subset of the neurons of the inner nuclear layer (possibly those that synthesize acetylcholine), the other retinal cells suffered no lasting damage that could be detected by either light or electron microscopy. Indeed, the photoreceptor cell itself remained morphologically stable after damage to the outer segment; its intracellular organelles appeared normal, and its synapses continued to convey information to cells postsynaptic to it. The integrity of the inner retina's circuits was further documented by the continued electrophysiological activity of the ganglion cells and by the fundamentally normal receptive field structure that could be observed in response to complex light stimuli. At the concentrations of HC-3 studied, the lesion is remarkably specific.

This specificity is probably due to the peculiar demands on the photoreceptor cell for phospholipid synthesis. There is no reason to think that IIC-3 does not acutely interfere with the choline metabolism of all retinal cells; the other cells are presumably spared damage because their rate of phospholipid renewal is so much less than that of the photoreceptors. The photoreceptor cells appear to be the only neurons of the central nervous system yet shown to have high affinity choline accumulation without using the choline for synthesis of acetylcholine. We now find that a transient, partial interruption of their choline supply has catastrophic consequences for outer segment structure. Taken together, these findings suggest that the demands of outer segment membrane renewal place the phospholipid metabolism of the photoreceptor cells in a relatively fragile balance.

Mechanism of the lesion. The first lasting abnormality observed after exposure of the retina to $\mathrm{HC}-3$ is the appearance of rows of vesicles at the base of the outer segment, the point where new membrane is normally added. The vesicles span the outer segment in rows, along the plane normally occupied by new discs. The formation of artifactual vesicles during aldehyde fixation has been reported (Hasty and Hay, 1978), but it does not seem likely that the vesicles seen here are artifactual. They are smaller (100 nm versus "several hundred to several thousand" nanometers) than the vesicles shown by Hasty and Hay, are rounder in shape, and are more
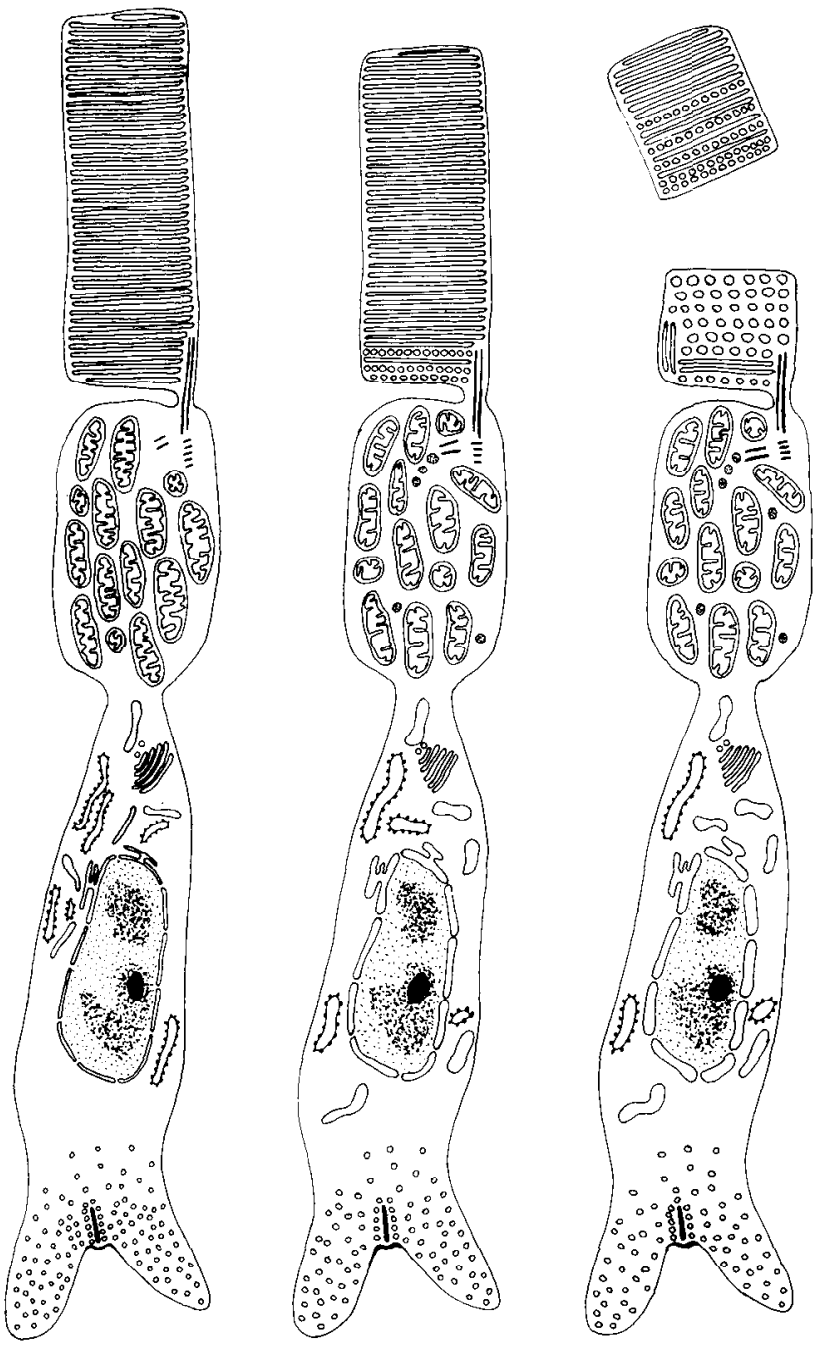

Control
1 Day
3 Days

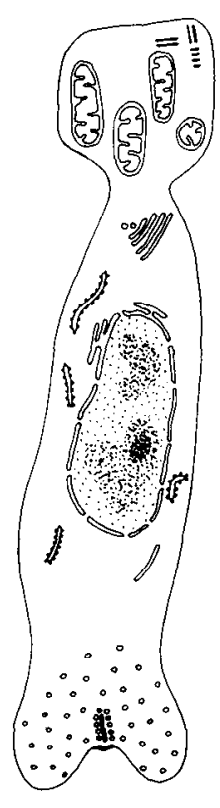

12 Days

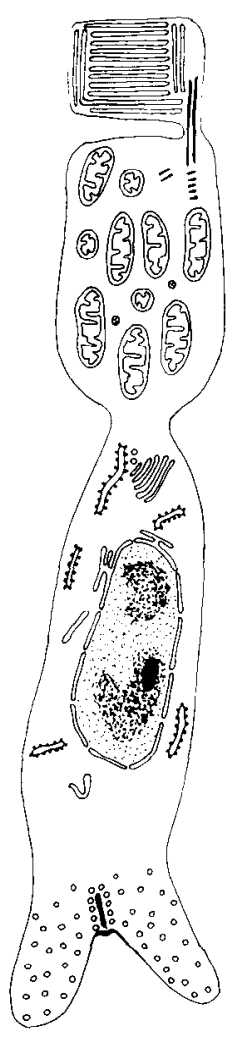

20 Days

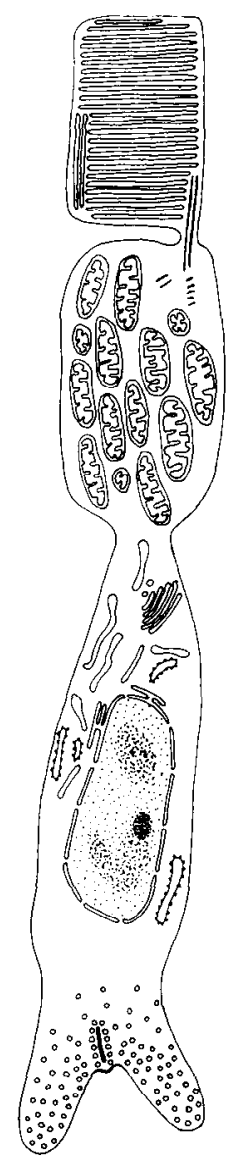

40 Days

Figure 19. Schematic diagram illustrating the effects of $20 \mu \mathrm{M} \mathrm{HC}-3$ on rabbit rod photoreceptor cells. 
regular in arrangement, spanning the outer segment in orderly rows (Fig. 8). In addition, one retina that showed the vesicles was fixed directly with $\mathrm{OsO}_{4}$, a condition under which the artifactual vesiculation was said not to occur. If the vesicles are an artifact, they are at least a consistent one: they were always observed in $\mathrm{HC}-3-$ treated retinas and never in control tissue. In either case, they would seem to indicate an instability of the new membrane added at the base of the outer segment.

One explanation of the action of HC-3 is that it causes an inappropriate phospholipid bilayer to be synthesized. This might be simply a membrane in which the normal ratios of the different phospholipid classes are disturbed, with the amount of phosphatidylcholine depressed but the amounts of the other phospholipids normal. Vesicles would form because the abnormal new membrane is unable to attain the (energetically unfavorable) flat disc configuration. This explanation is attractively simple and is in accord with the classically documented competitive inhibition of choline transport by $\mathrm{HC}-3$. Indeed, we have demonstrated directly (Fig. 2) that an effect of $\mathrm{HC}-3$ in the retina is to depress the rate at which extracellular choline enters into the pathway for de novo phosphatidylcholine synthesis.

However, it seems quite possible that more subtle effects of HC-3 on phospholipid metabolism also exist. For example, it is known that there are multiple pathways by which cells can maintain the phospholipid composition of their membranes. One of these is base exchange, which allows the interconversion of phospholipid classes (Mizuno, 1976). In addition, phosphatidylcholine can be synthesized without extracellular choline, by the successive methylation of phosphatidylethanolamine. Phosphatidylethanolamine is itself apparently formed by decarboxylation of phosphatidylserine (Anderson et al., 1980a). These mechanisms should tend to compensate for the loss of the phosphatidylcholine normally synthesized from free choline. In our experiments, the extent to which compensation occurred and its possible effect on the availability of phosphatidylserine and phosphatidylethanolamine (at whose expense compensation for a deficit of phosphatidylcholine would probably happen) are uncertain. Finally, it is known that $\mathrm{HC}-3$ itself is able to enter cells (Collier, 1973). It is conceivable that, once inside the cell, HC-3 could affect membrane phosphatidylcholine in ways other than simple choline deprivation.

It is of some interest that the vesicles seen by electron microscopy remain near the base of the rod outer segment. There is good evidence that the phospholipids of normal outer segments are very mobile; a newly inserted phospholipid molecule appears free to diffuse throughout the outer segment very soon after it is inserted into a basal membrane (Bibb and Young, 1974; Masland and Mills, 1979; Anderson et al., 1980b). If that is the case, an irregularity of phospholipid composition in new outer segment membranes should be quickly diluted among all of the outer segment membranes, rather than remaining confined to those near the outer segment's base. Perhaps the mobility of phospholipids is decreased in the $\mathrm{HC}-3$ treated retinas; if the new membranes in these retinas were as mobile as usual, pathology should have appeared almost simultaneously everywhere in the rod outer segment (as it did in cones).

Responses to light without outer segments. As the outer segments degenerated, there was a precipitous fall in the sensitivity of the photoreceptors to light; and at the time of maximum lesion, 12 days after injection of $\mathrm{HC}-3$, no electroretinogram could be recorded. Yet, light remained able to evoke a response from the ganglion cells-albeit with greatly reduced sensitivity-at every time studied following injection of $\mathrm{HC}-3$. There is no contradiction between the ability to record ganglion cell responses at 6 and 14 days and the failure to record an electroretinogram at 12 days. The electroretinogram is a field potential recorded at a large distance from the source of the current flow, and a small electroretinogram can easily be undetectable when there is still enough activity of the photoreceptors to transmit a signal to the proximal retina; the threshold of the electroretinogram is normally about a log unit higher than that of the ganglion cells (Weinstein, 1969). Light-evoked responses from the ganglion cells in these preparations thus imply that the photoreceptors are capable of transducing light (and transmitting that information to the bipolar cells) in the absence of an outer segment.

There is precedent for this finding. Rats with total loss of outer segments due to constant light exposure, and mice with inherited outer segment degeneration, have been reported able to perform visual discriminations, provided the stimulus is bright enough (Noell et al., 1966; Nagy and Misanin, 1970; LaVail et al., 1974). Szamier et al. (1979) studied a patient with advanced retinitis pigmentosa who was able to perceive light in some areas of the visual field despite a retina shown by postmortem light and electron microscopy to contain no outer segments in the corresponding regions. Finally, Drager and Hubel (1978) recorded from the superior colliculus of $r d$ mice and found unequivocal light-evoked responses at all stages of their hereditary photoreceptor cell degeneration, including times when not only were the outer segments gone but the outer nuclear layer was reduced to a single layer of cell bodies.

Clearly, the remaining part of the photoreceptor cell retains an ability to transduce light in these cases. How is this to be understood? It is known that the initial normal event in rod phototransduction is the absorption of light by rhodopsin, and that an eventual consequence of this absorption is the closing of $\mathrm{Na}^{+}$channels located in the outer segment plasma membrane. Since most of the outer segment rhodopsin is located in disks, this implies that rhodopsin somehow releases an internal transmitter which diffuses to the plasma membrane to close the $\mathrm{Na}^{+}$channels. The leading candidates for the internal transmitter are $\mathrm{Ca}^{++}$ions and cyclic GMP, but several other light-activated enzyme activities have also been identified (see O'Brien, 1982 for review). Presumably, after loss of the outer segment enough of the required proteins are present in membranes of the photoreceptor inner segment or cell body to allow the phototransduction observed in our experiments. There is evidence that rhodopsin is normally present in mammalian inner segments (Jan and Revel, 1974) and even if it is not, it (and other outer segment proteins) could 
be inappropriately inserted when the outer segment is absent. Since there are no disks in the inner segment, our experiments suggest that the sequestering of an internal transmitter within disks is not a necessary requirement for phototransduction, at least at a low level, to occur. Phototransduction under these conditions may resemble the process in cones, which lack enclosed disks and are less sensitive than rods.

\section{References}

Ames, A., III, and A. B. Hastings (1956) Studies on water and electrolytes in nervous tissue. I. Rabbit retina: Methods and interpretation of data. J. Neurophysiol. 19: 201-212.

Ames, A., III, and F. B. Nesbett (1981) In vitro retina as an experimental model of the central nervous system. J. Neurochem. 37: 867-877.

Ames, A., III, and D. A. Pollen (1969) Neurotransmission in central nervous tissue: A study of isolated rabbit retina. J. Neurophysiol. 32: 424-442.

Anderson, R. E., P. A. Kelleher, and M. B. Maude (1980a) Metabolism of phosphatidylethanolamine in the frog retina. Biochim. Biophys. Acta 620: 227-235.

Anderson, R. E., M. B. Maude, P. A. Kelleher, T. M. Maida, and S. F. Basinger (1980b) Metabolism of phosphatidylcholine in the frog retina. Biochim. Biophys. Acta 620:212-226.

Bibb, C., and R. W. Young (1974) Renewal of fatty acids in the membranes of visual cell outer segments. J. Cell Biol. 61: $327-343$

Birks, R., and F. C. MacIntosh (1961) Acetylcholine metabolism of a sympathetic ganglion. Can. J. Biochem. Physiol. 39: $787-827$.

Brown, K. T., and T. N. Wiesel (1961) Localization of origins of electroretinogram components by intraretinal recording in the intact cat eye. J. Physiol. (Lond.) 158: 257-280.

Bunt, A. H. (1978) Fine structure and radioautography of rabbit photoreceptor cells. Invest. Ophthalmol. Vis. Sci. 17: 90-104.

Collier, B. (1973) The accumulation of hemicholinium by tissues that transport choline. Can. J. Physiol. Pharmacol. 51: 491-495.

Drager, U. C., and D. H. Hubel (1978) Studies of visual function and its decay in mice with hereditary retinal degeneration. J. Comp. Neurol. 180: 85-114.

Geiman, Q. M., C. B. Anfinsen, R. W. McKee, R A. Ormsbee, and E. G. Ball (1946) Studies on malarial parasites. VIII. Methods and techniques for cultivation. J. Exp. Med. 84: 583-606.

Guyenet, P., P. Lefresne, J. Rossier, J. C. Beaujouan, and J. Glowinski (1973) Inhibition by hemicholinium-3 of ${ }^{14} \mathrm{C}$-acetylcholine synthesis and ${ }^{3} \mathrm{H}$-choline high-affinity uptake in rat striatal synaptosomes. Mol. Pharmacol. 9: 630-639.

Hasty, D. L., and E. D. Hay (1978) Freeze-fracture studies of developing cell surface. II. Particle-free membrane blisters on glutaraldehyde-fixed corneal fibroblasts are artifacts. J. Cell Biol. 78: 756-768.

Hayden, S. A., J. W. Mills, and R. H. Masland (1980) Acetylcholine synthesis by displaced amacrine cells. Science 210: $435-437$.

Holden, J. T., J. Rossier, J. C. Beaujouan, P. Guyenet, and J.
Glowinski (1975) Inhibition of high-affinity choline transport in rat striatal synaptosomes by alkyl bisquaternary ammonium compounds. Mol. Pharmacol. 11: 19-27.

Jan, L. Y., and J. -P. Revel (1974) Ultrastructural localization of rhodopsin in the vertebrate retina. J. Cell Biol. 62: 257273.

Jenden, D. J., J. Macri, M. Roch, and R. W. Russell (1977) Antagonism by deanol of some behavioral effects of hemicholinium. Commun. Psychopharmacol. 1: 575-580.

Lanum, J. (1978) The damaging effects of light on the retina. Empirical findings, theoretical and practical implications. Surv. Ophthalmol. 22: 221-249.

LaVail, M. M., M. Sidman, R. Rausin, and R. L. Sidman (1974) Discrimination of light intensity by rats with inherited retinal degeneration. A behavioral and cytological study. Vis. Res. 14: 693-702.

Masland, R. H., and A. Ames, III (1976) Responses to acetylcholine of ganglion cells in an isolated mammalian retina. J. Neurophysiol. 39: 1220-1235.

Masland, R. H., and C. W. Livingstone (1976) Effect of stimulation with light on synthesis and release of acetylcholine by an isolated mammalian retina. J. Neurophysiol. 39: 12101219.

Masland, R. H., and J. W. Mills (1979) Autoradiographic identification of acetylcholine in the rabbit retina. $J$. Cell Biol. 83: 159-178.

Masland, R. H., and J. W. Mills (1980) Choline accumulation by photoreceptor cells of the rabbit retina. Proc. Natl. Acad. Sci. U. S. A. 77: 1671-1675.

Maurice, D. M. (1976) Injection of drugs into the vitreous body. In Symposium on Ocular Therapy, Vol. IX, I. H. Leopold and R. P. Burnes, eds., pp. 59-72, John Wiley \& Sons, New York.

Mizuno, A. (1976) Incorporation of serine and ethanolamine into the phospholipids in rabbit retina. J. Biochem. 80: 4552.

Nagy, Z. M., and J. R. Misanin (1970) Visual perception in the retinal degenerate $\mathrm{C} 3 \mathrm{H}$ mouse. J. Comp. Physiol. Psychol. 72: $306-310$.

Noell, W. K., V. S. Walker, B. S. Kang, and S. Berman (1966) Retinal damage by light in rats. invest. Ophthalmol. Vis. Sci. 5: 450-473.

O'Brien, D. F. (1982) The chemistry of vision. Science 218: 961-966.

Osborne, M. P., and P. Monaghan (1976) Differential sensitivity of rods and cones in Xenopus retina to hemicholinium-3. Cell Tissue Res. 175: 59-72.

Sillman, A. J., H. Ito, and T. Tomita (1969) Studies on the mass receptor potential of the isolated frog retina. I. General properties of the response. Vis. Res. 9: 1435-1442.

Szamier, R. B., E. L. Berson, R. Klein, and S. Meyers (1979) Sex-linked retinitis pigmentosa: Ultrastructure of photoreceptors and pigment epithelium. Invest. Ophthalmol. Vis. Sci. 18: 145-160.

Weinstein, G. W. (1969) Electroretinographic and ganglion cell sensitivity in the isolated rat retina. Ophthalmologica 158 (Suppl.): 691-699.

Young, R. W. (1967) The renewal of photoreceptor cell outer segments. J. Cell Biol. 33: 61-72. 